\title{
Las cerámicas culinarias de Cabrera d'Anoia: Estrategias de producción en un alfar medieval'
}

\author{
Cooking vessels from Cabrera d'Anoia: Production strategies in a medieval \\ kiln site
}

José I. Padilla Lapuente *

Karen Alvaro Rueda *

Esther Travé Allepuz *

\begin{abstract}
RESUMEN
El alfar medieval de Cabrera d'Anoia (Barcelona) se impuso como gran centro productor, especializado en la elaboración de cerámicas de tipo culinario bajo cocción reductora, durante los siglos centrales de la Edad Media. La reciente aproximación desde una óptica arqueométrica al ingente volumen de materiales cerámicos recuperados en los testares de este alfar rural ha supuesto un avance significativo en el conocimiento de estas producciones, por lo general, escasamente definidas a nivel peninsular. Este estudio, que incluye la caracterización química, mineralógica y petrológica mediante Fluorescencia de Rayos $X$ (FRX), Difracción de Rayos X (DRX) y el estudio por petrografía cerámica de la producción a partir de la observación de láminas finas a microscopio polarizador, nos ha permitido crear la colección de referencia del alfar. La incorporación de estos datos a los resultados de las excavaciones realizadas a finales de los ochenta nos ofrece un panorama de conjunto que facilita la comprensión de las estrategias de producción y explotación del entorno en este centro singular que se mantuvo en activo durante más de tres siglos.
\end{abstract}

Palabras clave: Espacio artesanal, Alfar medieval, Producciones culinarias, Caracterización arqueométrica

\begin{abstract}
The medieval kiln site of Cabrera d'Anoia (Barcelona) was set up as a high impact producing centre specialized in utilitarian cooking wares fired in a reducing atmosphere during the main centuries of Medieval Ages. The recent approach from an analytical standpoint to the vast amount of pottery sherds rescued from the wasters' dump implied a significant improvement for the knowledge of such vessels scarcely characterized in the Iberian Peninsula, broadly speaking. This piece of research, including the chemical, mineralogical and petrographic characterization by means of X-Ray Fluorescence (XRF), X-Ray Diffraction (XRD) and observation of thin-sectioned samples under polarising microscope, has allowed the creation of a reference group for the kiln. The whole consideration of these data joined to the excavation results from the fieldwork carried out in late eighties offers a deep insight which facilitates the comprehension of the production and landscape exploitation strategies within this singular producing centre, active during more than three centuries.
\end{abstract}

Key words: Craftsmen's Workshop, Medieval Kiln Site, Cooking wares, Archaeometric Characterization.

I Este trabajo se ha desarrollado en el marco del Proyecto de Investigación HUM2007-6I55I, titulado El alfar medieval de Cabrera d'Anoia: Balance actual de las investigaciones arqueológicas y de laboratorio, del Plan Nacional de Investigación Científica 2008-20II y ha recibido el apoyo del Comissionat per a Universitats i Recerca del Departament d'Innovació, Universitats i Empresa de la Generalitat de Catalunya. Los autores desean hacer constar, en particular, su reconocimiento a los prof. J. Thiriot y H. Amouric y a otros investigadores del Laboratoire d'Archéologie Médiévale Méditerranéenne (Aix-en-Provence, CNRS. Université de Provence), por su valiosa contribución a la consecución de los objetivos del proyecto internacional sobre el alfar de Cabrera.

* Grupo de investigación de Arqueologia medieval y postmedieval [2009SGR00469]. Departamento de Historia Medieval, Paleografía y Diplomática. Facultad de Geografía e Historia. Universidad de Barcelona. 


\section{INTRODUCCIÓN}

El alfar de Cabrera d'Anoia es un centro artesanal dedicado a la elaboración de cerámicas comunes de uso culinario que debió alcanzar notoriedad a lo largo del siglo XIII. Las instalaciones alfareras formaban parte de un asentamiento aldeano, hoy en día desaparecido, que había surgido a la sombra de una fortificación altomedieval. Aquel castillo, que disponía de jurisdicción territorial sobre un pequeño distrito de relieve muy abrupto, ya aparece documentado desde la segunda mitad del siglo Xl.

Este despoblado medieval, que apenas conserva en pie algún testimonio aislado de su antigua fortificación, se encuentra situado sobre las estribaciones de la sierra prelitoral, a unos setenta kilómetros de Barcelona, cerca de la localidad de Capellades, en uno de los pasos naturales que comunica la depresión prelitoral y las comarcas interiores de Cataluña. A pesar de la ausencia de referencias documentales sobre la actividad artesanal, sabemos que el alfar de Cabrera llegó a distribuir sus manufacturas sobre un extenso ámbito regional. De este modo, cabe recordar que se trata de un alfar de prolongada trayectoria, que destaca por su elaboración exclusiva de formas comunes mediante viejos procesos productivos. Un buen ejemplo de centro artesanal tradicional que llegó a satisfacer un amplio sector de la demanda en base a un reducido repertorio de objetos culinarios.

Estos talleres productores de cerámicas tradicionales, que operaban bajo técnicas de cocción en atmósfera reductora, habían sido desplazados de las principales áreas urbanas en época gótica, pero se mantuvieron activos en el ámbito rural, aportando una producción común de carácter utilitario. Es verdad que las fórmulas tradicionales aplicadas en estas ollerías contrastan con el gran dinamismo que ya para entonces ofrecen las producciones urbanas, donde la división del trabajo había permitido la especialización cada vez mayor del oficio alfarero, con un artesanado abierto a las transferencias e innovaciones técnicas y una manufactura diversificada que satisfacía una demanda cada vez más exigente. Sin embargo, cabe reconocer el papel fundamental que estos centros rurales han venido a desempeñar en el aprovisionamiento de una vajilla funcional que se distribuye regularmente en el mercado rural, pero que llega incluso a penetrar en las cocinas urbanas. Desde esta perspectiva, el alfar de Cabrera constituye una referencia indispensable para el conocimiento de los procesos de producción y distribución de aquellos productos, así como un referente obligado entre los alfares tradicionales cerámicas culinarias del área mediterránea.

Las noticias sobre el hallazgo de cerámicas históricas en los aledaños del castillo de Cabrera se remonta a principios del siglo pasado (ROMANÍ, 1917). A pesar de la precocidad de estas informaciones, no será hasta 1974, cuando diversas obras de desmonte relacionadas con la urbanización de la zona desvelen una parte considerable de las instalaciones artesanales de este alfar medieval. Aquellos trabajos, que comprendían la abertura de una carretera y diversos viales secundarios, originaron un impacto notable sobre todo el sector, provocando la destrucción de amplias áreas del alfar. Aquella situación motivaría la realización de una intervención preliminar que reconoció el lugar, recolectó algunos materiales cerámicos y practicó varios sondeos a fin de evaluar el alcance del yacimiento (LÓPEZ, NIETO, 1979).

Tras aquella primera actuación de urgencia, habrá que esperar hasta finales de los 80 para que, dentro de un nuevo contexto y con renovadas perspectivas, resurja el interés por el yacimiento de Cabrera. Para entonces, las investigaciones sobre los alfares de cerámicas culinarias ya habían avanzado de forma considerable en otras regiones mediterráneas, rebasando el estudio de las estructuras de cocción y de la producción para afrontar el análisis global del área artesanal (THIRIOT 1986). En este nuevo marco de trabajo se planteará el proyecto conjunto para retomar el estudio del alfar de Cabrera con el objetivo de realizar un análisis exhaustivo de sus instalaciones, ya que el yacimiento ofrecía la posibilidad de analizar en detalle el área artesanal, a pesar de que buena parte de las estructuras de cocción hubieran sido arrasadas por las obras de desmonte. 
El nuevo proyecto de investigación se gestó a partir de un amplio acuerdo de colaboración entre las universidades de Barcelona y Aix-enProvence y el Laboratoire d'Archéologie Médiévale Mediterranéenne (ERA. 6 del CNRS) con el objetivo de impulsar un análisis exhaustivo del yacimiento por parte de sendos equipos de investigación que fueron coordinados por los profesores J. I. Padilla y Jacques Thiriot. Los trabajos arqueológicos se llevaron a cabo entre I987 y 199| en su etapa más activa, aunque las labores de campo aún se prolongarían hasta 1994, siendo sufragados con cargo a las ayudas del Departament de Cultura de la Generalitat de Catalunya y del Ministère des Affaires Étrangères del Gobierno de Francia.

El proyecto persiguió desde sus comienzos la necesidad de reconocer desde un punto de vista pluridisciplinar las pautas de ocupación de la actividad artesanal y la dinámica de transformación del paisaje, a efecto de contribuir a la reconstrucción paleoambiental del área artesanal y resolver la probable evolución tipológica de las producciones de este alfar (LEENHARDT et alii, 1993 Y 1995). De este modo y de forma paralela a los últimos trabajos de campo (PadiIla, Vila, 1998), se inicia un conjunto amplio de investigaciones de laboratorio sobre el alfar de Cabrera y sus producciones, que se han prolongado hasta nuestros días. Entre las que cabe destacar, por ejemplo, la datación de un conjunto de muestras mediante radiocarbono y arqueomagnetismo (PADILLA et alii, 1999) o la primera aproximación a la producción del alfar a través de los materiales de los testares (PADILLA, VILA, 1997); Así como, otros trabajos en relación con la explotación de la cubierta vegetal y la evolución del paisaje desde la óptica de la antracología (PY, 200I) o la caracterización química de arcillas y los procesos de cocción empleados en el alfar (PRADELL, 1992).

En estos últimos años hemos llevado a cabo, en el marco de un proyecto de investigación financiado por el Ministerio de Ciencia e Innovación, un amplio balance de los resultados obtenidos a fin de fijar el estado actual de las investigaciones sobre este alfar. Estos trabajos nos han permitido realizar una nueva lectura de la documentación generada por los trabajos de excavación, sentando las bases para acometer con éxito el estudio arqueológico y la caracterización arqueométrica de la producción. De este modo, este proyecto de síntesis ha logrado, por un lado, avanzar de forma global en la definición del sistema de producción en gruta a partir de la explicación de este yacimiento paradigmático (PADILLA et alii, 2008) y, por otro, ha conseguido aproximarnos a partir de los estudios analíticos, que combinan la petrografía cerámica con la Fluorescencia de Rayos- $X$ y la Difracción de Rayos-X, a las técnicas empleadas en la producción del alfar.

De esta forma, el trabajo que presentamos da a conocer los resultados preliminares de la caracterización arqueométrica de la producción del alfar. Los nuevos datos ofrecen, además, una información precisa en relación a la proveniencia de la materia prima, al modo de preparación de la pasta, a las técnicas de modelado y a la temperatura de cocción. Estos resultados, que han aportado algunas novedades significativas en el estudio de la tecnología de producción de estas cerámicas culinarias, deberán ser cotejados en el futuro con nuevos muestreos a fin de definir con precisión las técnicas y procesos empleados en estos alfares rurales.

\section{UN MODELO DE TALLER EN GRUTA}

Este estudio centra su atención en las producciones cerámicas elaboradas en este alfar, así como en los problemas relativos a su tecnología de producción. Sin embargo, parece necesario describir, aunque sea brevemente, las características generales de este centro productor, a fin de comprender la importancia del modelo artesanal que aquí se enuncia. De esta forma, enunciaremos brevemente los elementos más relevantes de las instalaciones y la evolución de este alfar, así como de lo que entendemos como sistema de producción en gruta, aspectos que ya tuvimos ocasión de desarrollar más ampliamente en una ocasión precedente (PADILLA et alii, 2008).

Los talleres en gruta responden a un modelo de producción que utiliza de forma ventajosa las características del relieve y del contexto 
geológico para desarrollar su actividad artesanal sobre un espacio físico limitado y sometido a constantes transformaciones. De esta forma, los alfareros se ven obligados ante la limitación del espacio disponible a una gestión eficaz del área de trabajo, mediante un proceso de constante adaptación del sector, a fin de aprovechar en lo posible las condiciones del emplazamiento. Sin embargo, las características de un medio natural particularmente agreste no parecen aportar ningún aspecto disuasorio para el establecimiento de estos alfares tradicionales, ya que su instalación parece relacionarse más con la protección que ofrecen los abrigos naturales, así como con la presencia de un sustrato geológico necesario donde realizar la excavación de las estructuras de cocción.

De esta forma, el concepto de taller en gruta lleva aparejado el principio de constante transformación del espacio artesanal, por cuanto los factores naturales y antrópicos interactúan de forma permanente, provocando la modificación continua del medio y de las áreas de trabajo. Estas condiciones no son exclusivas del alfar de Cabrera, ya que otros centros productores del área mediterránea ofrecen en mayor o menor medida esta problemática, como es el caso de algunos alfares provenzales de época moderna (AMOURIC et alii, 1995).

Por otra parte, la utilización de sustratos geológicos de características definidas, fáciles de excavar, parece vincularse con la instalación de estos centros productores de cerámicas culinarias que desarrollan estructuras de cocción de tiro vertical con parrilla o solera entre ambas cámaras. En estos casos, la cámara de fuego y solera se acondicionan a partir de la excavación del nivel geológico, mientras las partes altas de la estructuras son construidas en su práctica totalidad. La necesidad de contar con un nivel geológico que permita la excavación de la solera constituye un aspecto relevante en centros como, por ejemplo, Saint-Victor-des-Oules - Casampons, aunque en ambos casos nos hallamos ante alfares que se asientan sobre un terreno más o menos llano (THIRIOT, 1980). Algo parecido sucede con la mayoría de pequeños talleres de cerámicas culinarias conocidos en Cataluña, donde la técnica de excavación de los hornos es similar con independencia del tipo de asentamiento de que se trate (figura I).

Las evidencias artesanales, que pudieron ser reconocidas en los trabajos de excavación, se asentaban a lo largo de tres plataformas sucesivas dispuestas al pie de diversos escarpes rocosos, a unos doscientos metros del núcleo habitado. Cabe advertir que el área sólo representa un sector reducido del alfar, ya que las actividades alfareras fueron desplazándose a lo largo de la vida útil de este centro productor A pesar de esta circunstancia, los testimonios conocidos, que corresponden a las fases más tardías, constituyen una muestra significativa de la organización artesanal de este centro productor.

El área de estudio ofrece un relieve extremadamente accidentado, con importantes taludes y pronunciadas pendientes, estando presidido por potentes depósitos de travertino que cubren una extensión considerable del sector. Los límites de estas formaciones presentan grandes frentes escarpados hacia levante, dejando al descubierto en algunas áreas el estrato geológico (granodiorita) sobre el que se depositaron aquellas formaciones sedimentarias. Al pie de los cortados, que encabezan de forma predominante el relieve, se encuentran las instalaciones alfareras, mientras que el terreno circundante ofrece una pronunciada pendiente que desciende hasta el cauce fluvial (figura 2).

La mayor parte de las instalaciones han sido acondicionadas a partir del aprovechamiento extensivo del nivel de granitoide, como ocurre, por ejemplo, con las estructuras de cocción. Los hornos de Cabrera corresponden, como hemos enunciado en diversas ocasiones, a un modelo frecuente de horno medieval (PADILLA et alii, 2008). Se trata de una estructura, de tiro vertical, formada por dos cámaras superpuestas, separadas entre sí por una parrilla o solera atravesada por un número variable de conductos o chimeneas. De este modo, la cámara inferior o de combustión, así como la parrilla, se encuentran excavadas en el granito meteorizado, mientras que la cámara superior o de cocción está construida a base de adobes de arcilla semicocida. 
Las dimensiones de estos hornos, que adoptan en planta formas elípticas o circulares, ofrecen, por término medio, un diámetro aproximado de $150 \mathrm{~cm}$, aunque se documentan algunas estructuras coetáneas de un diámetro claramente superior. La cámara de cocción, que dispone por lo general de un diámetro similar al de la cámara de fuego, se encuentra separada de aquélla mediante una solera que puede superar con frecuencia el medio metro de espesor.

La excavación de los hornos se efectúa a niveles más o menos profundos del granito meteorizado, por lo que es preciso acceder hasta la puerta de la cámara de combustión mediante una fosa de dimensiones variables. Por su parte, la cámara de cocción no parece disponer en estos casos de puerta específica para enfornar, por lo que es probable que dicho elemento no contara con cubierta permanente. La ausencia de dicha cubierta no plantea ningún problema técnico para el desarrollo de una cocción en atmósfera reductora, como puede comprobarse a nivel de los testimonios etnoarqueológicos.

Las limitaciones del espacio útil disponible imponen la necesidad de aplicar determinadas estrategias sobre el área de trabajo que son reconocibles en la evolución de las actividades artesanales. De esta forma, son apreciables tanto la necesidad de obliterar con rapidez las estructuras abandonadas a fin de reacondicionar el área, como la recuperación parcial de los hornos obsoletos. En este caso, la cámara de combustión del horno inutilizado se convierte en la fosa de acceso para la excavación y uso de una nueva estructura (figura 3). La aplicación continuada de este proceso, que economiza el espacio y construye con menor esfuerzo la nueva estructura, ha generado series de cuatro a cinco estructuras, que siguen el principio de alineación frontal característico de este alfar (LEENHARDT et alii, 1995).

Sin embargo, es preciso recordar que existe una cadencia en esta dinámica de cambio, una suerte desplazamiento continuo de los hornos, que afecta necesariamente al espacio disponible. La consistencia de la granodiorita meteorizada, que ha permitido la construcción de los hornos, es, a su vez, la causa fundamental de su fragilidad. Las estructuras de cocción sufren continuas tensiones a lo largo de su utilización que tienden a reducir su vida útil. El deterioro se hace evidente sobre las partes más expuestas de la estructura, generando grietas y fractura de mayor o menor entidad. La rápida degradación, que puede ser ralentizada por acciones sucesivas de reparación del alfarero, acabará imponiendo antes o después la necesaria sustitución de todo el horno (figura 4).

De este modo, el desarrollo de la actividad artesanal impone el desplazamiento continuo de las instalaciones y el consumo gradual del espacio útil. Una dinámica que logra agotar las posibilidades del espacio de trabajo y obliga al abandono del sector con la abertura y acondicionamiento de nuevos ámbitos. Así, las estructuras del alfar parecen desplazarse hacia el área septentrional, respondiendo a una tendencia permanente de evolución lateral para dar respuestas a las reducidas dimensiones con que cuentan los espacios de trabajo. Una secuencia de ocupación, reutilización y abandono que se muestra especialmente evidente en la terraza intermedia, en el sector donde se documenta el mayor número de estructuras (figura 5).

La necesidad de adaptación permanente a un espacio de trabajo limitado hace que buena parte de las actividades se concentre en los obradores rupestres. Estos espacios, que tuvieron en algún momento funciones de obrador, han sufrido también un proceso de desplazamiento continuo, similar al descrito para las plataformas a cielo abierto donde se excavan los hornos, ya que ambos espacios funcionan de forma integrada.

Conocemos cuatro áreas de taller u obrador, dos corresponden respectivamente a la terraza superior e intermedia (obrador I y 2), mientras las dos restantes formaban parte de la plataforma inferior (obrador 3 y 4). Los dos primeros ofrecieron trazas tenues que permitían establecer algunas hipótesis sobre su utilización, pero habría de ser la excavación del obrador 3 la que aportará los mayores indicios para la interpretación conjunta de estos espacios 
artesanales. En todos los casos, estas cavidades parecen haber tenido un origen natural, aunque su transformación en abrigos artificiales se debió producir a partir de la extracción de grandes volúmenes de granodiorita. Estos espacios a cubierto ofrecían las condiciones para ser transformados en áreas donde realizar las operaciones de preparación, modelado y secado de las piezas.

El espacio rupestre correspondiente al obrador 3 ha conservado, a diferencia de los restantes talleres conocidos, la fisonomía general que tenía en época medieval. En este caso, el estudio del sector ofrece datos precisos sobre la ampliación del abrigo a partir de dos minas que avanzan lateralmente en direcciones opuestas. Dicho origen determina los rasgos principales de la futura gruta, quedando consolidados tras su adecuación como área de obrador. Se trata de una gruta de dimensiones aceptables, de unos $30 \mathrm{~m}^{2}$ de superficie útil, que podemos distribuir en dos ámbitos diferenciados. El área meridional del obrador es un espacio reducido, que parece haber tenido una función claramente auxiliar. El ámbito septentrional, por el contrario, es un espacio de mayores dimensiones y algo mejor acondicionado, que ofrece las principales trazas que sugieren su utilización como obrador. En el fondo de la gruta y en el espacio divisorio entre ambos ámbitos, se localizó un silo que se relaciona con las actividades alfareras y la conservación de la materia prima (PADILLA, VILA, 1998).

En el fondo de la covacha, se apreciaban, además, algunos encajes que permite suponer la existencia de algún tipo de estructura de madera relacionada quizás con el secado de las piezas o con alguna de las actividades del obrador. Por otra parte, se registra un gran bloque de travertino en forma de paralelepípedo con una cara regular que ha podido ser utilizado para el amasado preliminar de la arcilla, así como un pequeño hogar y los restos del muro de cierre de la estancia. Sin embargo, no existen evidencias palpables en los suelos de los obradores de anclajes o perforaciones donde fijar una estructura de torno de tipo permanente, por lo que debemos descartar la utilización del torno alto o de pie frente a otros artificios móviles. Las características de la producción, que analizaremos más adelante, vienen a corroborar el uso generalizado de la torneta como instrumento habitual entre los alfareros de este alfar.

El proceso de ocupación de los obradores está estrechamente relacionado con la evolución de las plataformas cercanas donde se construyen y amortizan las estructuras de cocción. Ambos espacios son complementarios y ofrecen también en cada caso un periodo no siempre coincidente de utilización en el tiempo. Los espacios de obrador, como ocurre con las estructuras de cocción y el espacio a cielo abierto, cuentan a su vez con una vida limitada dentro de una transformación incesante del paisaje artesanal. El techo de los improvisados obradores ha cedido, con frecuencia, provocando el hundimiento de las placas de travertino y el abandono del emplazamiento.

Sin embargo, la amenaza de derrumbe de las cubiertas no siempre ha supuesto el traslado inmediato del área de trabajo. En el obrador 2, por ejemplo, parece establecerse una secuencia de utilización que se inicia con la ocupación de la gruta. A medida que el techo se desploma el espacio parece continuar en funcionamiento, como si se tratara de un abrigo más. Más adelante, el taller queda al aire libre, pero sólo el agotamiento de la terraza acabará forzando el traslado del obrador a la terraza superior (LEENHARDT et alii, 1993).

\section{Cronología de las instalaciones y de la producción}

La transformación del espacio artesanal y las serias amputaciones que ha sufrido el yacimiento dificultan la reconstrucción de la secuencia cronológica en que se ordenan las diversas instalaciones del taller. En este sentido, debemos reconocer que la información sobre las instalaciones del alfar es claramente fragmentaria, ya que no disponemos de testimonios de todas las fases de actividad de este centro productor. Aun así, cabe asumir el riesgo que comporta la lectura de estas evidencias fragmentarias para avanzar en una propuesta de periodización de las etapas mejor conocidas (figura 6). 
La sucesión de las estructuras y otras evidencias señalan un avance de las instalaciones hacia el sector más septentrional, aspecto que concuerda con el desplazamiento continuado que parece haber impulsado el alfar. De este modo, buena parte de los testimonios más antiguos se han perdido definitivamente, ya que la terraza inferior apenas aporta referencias significativas en tal sentido. Por el contrario, los restos mejor conservados son los situados sobre las terrazas superior e intermedia y corresponden a las fases finales del taller.

Las informaciones disponibles parecen indicar que se han perdido, además, las evidencias relacionadas con una etapa intermedia del taller que habrían actuado de nexo de unión entre lo que denominamos fase antigua y las fases finales del alfar. Esta interpretación parece cobrar sentido al observar con detenimiento la disposición de las estructuras en la terraza intermedia, ya que la primera alineación de hornos no se conserva de forma íntegra. Cabe pensar que las estructuras de cocción conocidas pudieron ser precedidas por otras estructuras más antiguas que desaparecieron con la construcción de la pista.

Poco más podemos aportar respecto de las fases antiguas del taller, salvo que debieron de estar en funcionamiento a principios del siglo XII, ya que hacia la segunda mitad del XII estos espacios parecen hallarse claramente amortizados. De la producción correspondiente a esta etapa apenas hemos conservado un pequeño testimonio, que procede del testar antiguo (UE. 120) localizado en el ámbito menor de la gruta obrador 3, cuyo origen es posterior al abandono de la gruta.

Sin embargo, contamos con mucha mayor información para reconstruir la actividad en las terrazas superiores, allí donde se concentra el mayor número de estructuras. Es probable que la actividad artesanal hubiera alcanzado la terraza intermedia en una fecha temprana, así parece atestiguarlo la datación correspondiente a la gruta obrador de dicha plataforma. En cualquier caso, parece más que probable que el sector estuviera activo mucho antes de que el espacio de la terraza inferior se hallara en su etapa final.

La batería de estructuras de la plataforma intermedia correspondientes a los hornos CDA.99.H, AC, X, W, P, Q y R habría funcionado a pleno rendimiento, según indican las dataciones absolutas, durante los últimos años del XII y los primeros del siglo XIII. Dichas estructuras deben relacionarse con la utilización de la gruta obrador 2, a pesar de que todavía los hornos se disponen sobre la línea de pendiente a cierta distancia de la gruta (PADILLA et alii, 1998). No conservamos materiales de esta fase, ya que la mayor parte de los testares originados por estos hornos desaparecieron desde antiguo al rodar por la vertiente.

Es probable que a mediados del siglo XIII, el avance de las estructuras hacia la gruta fuera un hecho comprobable. A diferencia de lo ocurrido con los residuos antiguos, las nuevas limpiezas de los hornos no logran alcanzar la vertiente, de modo que colmatan gradualmente las estructuras obsoletas. La producción del momento queda bien documentada gracias a los materiales procedentes del gran testar (UE. 374), creado a partir de la actividad de los hornos CDA.99.Y, M y TI, que cubre las estructuras de finales del XII. El hallazgo de un dinero de Pedro el Católico (I 196-1213) sobre la superficie anterior a la deposición de los residuos, nos indica que tanto éstos como los hornos que los producen estaban en actividad en pleno siglo XIII, una precisión que no entra en contradicción con las dataciones obtenidas por radiocarbono.

Hacia finales del siglo XIII es probable que las instalaciones en uso de la plataforma se hubieran acercado hasta los límites de la gruta obrador. Las principales alineaciones del sector parecen definitivamente amortizadas, aunque prosigue la actividad en los hornos CDA.99.T, F y A. Las últimas estructuras de la terraza intermedia seguirán en funcionamiento durante el siglo XIV, aunque ya para entonces las actividades del alfar se habían trasladado a la terraza superior, tal vez por el desplome parcial de la gruta. 
El horno CDA.99.A y las estructuras vinculadas al obrador de la terraza superior son, en efecto, las estructuras que parecen ofrecer una cronología más tardía. El citado horno representa la última estructura en actividad en la plataforma intermedia y sus limpiezas han amortizado de forma definitiva la fosa de acceso a la estructura CDA.99.F. Por su parte, la utilización de la gruta obrador de la terraza superior parece haberse mantenido en actividad hasta un momento avanzado del siglo XIV. En definitiva, la secuencia cronológica corrobora un modelo de explotación que, partiendo de las limitaciones que impone el medio natural, ha logrado acomodar un espacio de trabajo para desarrollar sus actividades artesanales. Un espacio que avanza hacia nuevas áreas a medida que los sectores en uso quedan agotados por el desarrollo de la actividad artesanal.

De todas formas, la exposición precedente sólo es un breve resumen sobre las características principales de este centro productor. Una visión de conjunto que, en cualquier caso, es necesaria antes de abordar el análisis de la producción. Veamos, a continuación, las características morfológicas y arqueométricas de los productos elaborados en este alfar, así como algunos aspectos relacionados con su tecnología de producción.

\section{LA CARACTERIZACIÓN DE LA PRODUCCIÓN}

\section{Los aspectos morfológicos}

El alfar de Cabrera d'Anoia es un centro especializado en la manufactura de formas culinarias mediante procesos de producción en atmósfera reductora. Una producción, en cualquier caso, de marcado carácter utilitario, con un reducido repertorio de formas, que presentan pastas groseras, grises a negruzcas, y ofrecen superficies ligeramente alisadas. Las primeras aproximaciones a la producción ya señalaron el papel preponderante de las formas tipo olla en todos los contextos materiales analizados (LEENHARDT et alii, 1993Y 1995).
Por otra parte, algunos de los criterios conocidos inicialmente a través del estudio del gran testar de la terraza intermedia (PADILLA, VILA, 1997), se pudieron corroborar al hacer extensivo el estudio al conjunto de la producción y no variar de forma significativa sus rasgos generales. De todos modos, el conjunto de materiales puede clasificarse, como veremos a continuación, en: formas cerradas, formas abiertas y otras formas (figura 7).

Las formas cerradas constituyen el grupo mayoritario (95\% de la producción), siendo la más frecuente la forma tipo olla. En este caso, podemos distinguir dos variantes formales: Por un lado, las ollas de cuerpo globular o casi esférico, con bordes vueltos y labios adaptados para el uso de tapaderas; $y$, por el otro, las ollas bitroncocónicas con marcadas carenas, fondos ligeramente convexos y bordes similares a los anteriores. Dichas formas se presentan en la muestra bajo tres versiones o formatos más o menos estandarizados, siendo preponderantes las ollas de volumen intermedio, que ofrece por término medio unos $20 \mathrm{~cm}$ de diámetro.

Próximas a las formas tipo olla se encuentran otras formas cerradas de cuerpo más o menos esférico, que aparecen relacionadas con el trasiego de líquidos como los jarros y cannatae. Las formas de este tipo guardan una gran similitud formal con el prototipo de olla en esta producción tradicional, ya que su distinción sólo obedece a la incorporación de una vertedera pinzada o tubular que se complementa con un asa de cinta situada en la parte opuesta. La alta fragmentación del material y la presencia reducida de estos elementos aplicados pueden haber reducido la representatividad real de estas formas, aún así no parece probable que llegaran a tener una presencia relevante en el conjunto.

Las formas abiertas constituyen un grupo mucho más reducido y heterogéneo, que no llega a superar el $2 \%$ de las formas identificadas. La forma abierta más habitual es la cazuela baja, de paredes reforzadas con pronunciada carena y fondo convexo, que ostenta, por lo general, dos pequeñas asas de cinta enfrenta- 
das y una vertedera pinzada sobre el borde. Por otra parte, cabe destacar la presencia en algunos contextos de formas tipo lebrillo, con paredes ligeramente arqueadas, base plana y cuerpo alto, destinado a múltiples usos. Y, finalmente, aparecen de forma testimonial algunas formas poco habituales entre la producción del alfar como algunos cuencos o escudillas simples y alguna sartén.

En último lugar, cabe hacer referencia al grupo de formas auxiliares que comprende básicamente la elaboración de tapaderas circulares, de base plana, destinadas a servir de cubierta a las ollas. Estas piezas, que ofrecen un diámetro alrededor de los $20 \mathrm{~cm}$, se caracterizan por sus rebordes levantados y la presencia de un asa de cinta sobre la parte superior de la pieza, pudiendo presentar alguna decoración simple en base a digitaciones dispuestas en forma de cenefa.

Las formas no suelen presentar tratamientos de superficie complejos, más allá de un alisado general, que no siempre oculta los retoques manuales e imperfecciones del proceso de modelado. El conjunto de la producción ofrece, ocasionalmente, motivos decorativos incisos, en donde predominan los trazos horizontales $u$ ondulados situados preferentemente sobre la parte superior de las ollas, que pueden aparecer asociados a otras formas simples de impresiones, undulaciones o marcas.

Los alfareros de esta ollería han centrado sus esfuerzos en la producción de un reducido muestrario de formas que se ha mantenido con ligeras variaciones a lo largo del tiempo. De forma que una cierta monotonía morfológica parece presidir las diversas fases de producción, ya que no se perciben cambios o variaciones significativas desde el punto de vista tipológico. El carácter eminentemente funcional de la producción prima por encima de otros aspectos. La robustez y, particularmente, el carácter culinario de estos productos han aportado el atractivo e interés por estas formas tradicionales que tenían la virtud de soportar su exposición al fuego y, acaso, permitían algunas prácticas culinarias exclusivas.
La producción del alfar se ha encaminado a la elaboración de ollas y, en menor medida, cazuelas, así como algunos recipientes de grandes dimensiones y otros tipos de contenedores. La percepción general sobre el material cerámico de este alfar sugiere que no existen cambios significativos en los rasgos generales de la producción. Sin embargo, el estudio detallado del conjunto detecta algunas sutiles variaciones, por ejemplo en la morfología de los labios y bordes de las formas tipo olla, que se corroboran a través de las diferencias que ofrecen los estudios arqueométricos.

Se percibe, por ejemplo, que las piezas más antiguas presentan bordes simples, de labio redondeado o ligeramente pinzado, con una apariencia general oscura y algo más fina que en épocas posteriores. Sin embargo, a medida que avanza el siglo XIII, las ollas parecen contar con bordes y labios mucho más elaborados, donde predominan los labios compuestos y engrosados, con acanaladuras y aristas, que denotan un dominio eficiente de la técnica del modelado y una cierta preocupación por el acabado final del producto. Por contra, a medida que finaliza el siglo XIII y nos adentramos en el XIV se produce un proceso de simplificación en la elaboración del borde de las piezas, que presentan labios sencillos, ligeramente engrosados y pinzados, y en ocasiones adaptados para acoger la tapadera. Una tendencia que se acentuará aún en mayor medida hacia la etapa final de la producción (figura 8).

\section{La caracterización arqueométrica}

El estudio analítico de las pastas se ha llevado a cabo sobre una muestra significativa compuesta por un centenar de individuos seleccionados a partir de una observación macroscópica del conjunto. El estudio morfológico de estos materiales, que presentan pastas groseras con abundantes desgrasantes, ha dado paso a un análisis pormenorizado de las pastas.

Este trabajo ha permitido seleccionar para cada unidad estratigráfica analizada un número de muestras proporcional, de modo que el 
conjunto final viniera a reflejar la producción elaborada por el alfar. La mayor parte de las muestras de cada unidad han sido seleccionadas atendiendo a su representatividad en el conjunto, mientras se reservaba un $10 \%$ del material escogido para aquellas piezas que presentaran alguna singularidad que las distinguiese del conjunto, ya fuera por el tamaño de las inclusiones, textura de la pasta, características de la fractura o coloración.

Esta selección pretendía esclarecer los problemas de proveniencia de la materia prima empleada, así como las técnicas de producción y las posibles variaciones introducidas en el transcurso del tiempo. Las muestras seleccionadas fueron preparadas para su análisis por Fluorescencia de Rayos-X (FRX), Difracción de Rayos-X (DRX) y observación a microscopio polarizador. La aplicación de estas tres técnicas analíticas nos ofrece, respectivamente, una aproximación fiable a su composición química, mineralógica y petrológica, que puede ser interpretada científicamente de cara a resolver las cuestiones planteadas en relación a la producción de este alfar (TRAVÉ, 2009).

El dendrograma obtenido del análisis de agrupación realizado con los resultados obtenidos por FRX permite apreciar claramente la presencia de tres grupos químicos principales, a los que hemos convenido en denominar CDAI, CDA2 y CDA3 (figura 9). Los mencionados grupos composicionales parecen corresponder a tres fases de producción del taller, como veremos más adelante al analizar los resultados del estudio petrográfico. El gráfico representa a todos los individuos de la muestra, que se ordenan siguiendo un proceso jerárquico de agrupación hasta lograr alcanzar un tronco común. De este modo, cuanto más alejada de la base se produzca la aglomeración o unión, más desiguales en composición química son los individuos que se unen. Así, podemos comprobar como los grupos muestran una gran heterogeneidad y su diferenciación es sutil, aunque también se aprecian los individuos que determinan el núcleo duro de cada grupo.

Las características químicas principales de cada grupo han sido definidas a partir de un análisis de componentes principales, que han permitido detectar, además, la relación que guardan los distintos grupos con cada uno de los individuos. Esta técnica estadística nos permite hallar combinaciones lineales de los componentes iniciales que maximizan la variabilidad en un número reducido de componentes. De esta forma, se consigue pasar de un número elevado de dimensiones a un pequeño número de valores calculado como combinaciones de estas concentraciones. Así, es posible confeccionar gráficos bivariantes, como los que mostramos a continuación, que correspondan a estas nuevas combinaciones o componentes principales.

Este tipo de representación siempre ofrecerá una varianza mayor que cualquier gráfico bivariante realizado sobre las concentraciones iniciales. De este modo, se sintetiza en un único gráfico una mayor cantidad de información que permite analizar con más precisión la estructura de los grupos existentes en el conjunto de individuos de la muestra. Esta representación permite, además, incluir la situación de los componentes iniciales, es decir, de los elementos químicos para poder apreciar mejor que es lo que caracteriza las diferencias y similitudes entre los distintos individuos y grupos.

Los coeficientes de los tres primeros componentes principales, que explican el $82.56 \%$ de la varianza, puede apreciarse en la tabla adjunta (figura I0). Los valores de los coeficientes para el primer componente principal $(\mathrm{Cl})$, que explica el $57.79 \%$ de la varianza, presentan atracción hacia $+\mathrm{Cl}$ de los $\ln \left(\mathrm{Zr} / \mathrm{Al}_{2} \mathrm{O}_{3}\right)$ y de los $\ln \left(\mathrm{MnO} / \mathrm{Al}_{2} \mathrm{O}_{3}\right)$ principalmente, en cierta oposición con los $\ln \left(\mathrm{CaO} / \mathrm{Al}_{2} \mathrm{O}_{3}\right)$, els $\ln (\mathrm{MgO} /$ $\left.\mathrm{Al}_{2} \mathrm{O}_{3}\right)$, y los $\ln \left(\mathrm{Sr}_{\mathrm{A}} \mathrm{Al}_{2} \mathrm{O}_{3}\right)$ principalmente, atraídos por $-\mathrm{Cl}$. Los coeficientes del segundo componente principal (C2), que explica el 13.82\% de la varianza presentan atracción hacia $+\mathrm{C} 2$ de los $\ln \left(\mathrm{Cu} / \mathrm{Al}_{2} \mathrm{O}_{3}\right)$ y de los $\ln \left(\mathrm{Zn} / \mathrm{Al}_{2} \mathrm{O}_{3}\right)$ principalmente, en cierta oposición con los $\ln \left(\mathrm{Na}_{2} \mathrm{O} / \mathrm{Al}_{2} \mathrm{O}_{3}\right)$ y los $\ln \left(\mathrm{Ba} / \mathrm{Al}_{2} \mathrm{O}_{3}\right)$ principalmente, atraídos por - $\mathrm{C} 2$. Finalmente, los coeficientes del tercer componente principal (C3), que explica el $10.95 \%$ de la varianza, presentan atracción hacia $+\mathrm{C} 3$ de los $\ln \left(\mathrm{Na}_{2} \mathrm{O} / \mathrm{Al}_{2} \mathrm{O}_{3}\right)$ y de los $\ln \left(\mathrm{Cr} / \mathrm{Al}_{2} \mathrm{O}_{3}\right)$ principalmente, en cierta 
oposición con los $\ln \left(\mathrm{K}_{2} \mathrm{O} / \mathrm{Al}_{2} \mathrm{O}_{3}\right)$ y los $\ln (\mathrm{Ni} /$ $\mathrm{Al}_{2} \mathrm{O}_{3}$ ) principalmente, atraídos por $-\mathrm{C} 3$.

En las figuras se puede observar el análisis de componentes principales transformados en logaritmos de razones empleando el $\mathrm{Al}_{2} \mathrm{O}_{3}$ como divisor sobre la misma subcomposición que en el dendrograma. La representación de los In en los ejes definidos para Cl y C2 (figura I la), que explican el $71.61 \%$ de la varianza, permite observar como el primer componente principal es el responsable de la distinción entre las agrupaciones de CDAI y CDA3 atraídas por $+\mathrm{Cl}$, hecho que nos indica una riqueza mayor en las fases de $\ln \left(\mathrm{Zr} / \mathrm{Al}_{2} \mathrm{O}_{3}\right)$ y $\ln (\mathrm{MnO} /$ $\mathrm{Al}_{2} \mathrm{O}_{3}$ ), en contraposición con el grupo CDA2 atraído por $-\mathrm{Cl}$, que presenta por el contrario una riqueza mayor en $\ln \left(\mathrm{CaO} / \mathrm{Al}_{2} \mathrm{O}_{3}\right)$, $\ln (\mathrm{MgO} /$ $\left.\mathrm{Al}_{2} \mathrm{O}_{3}\right)$, y $\ln \left(\mathrm{Sr}_{\mathrm{Al}} \mathrm{Al}_{2} \mathrm{O}_{3}\right)$. El primer componente principal nos permite definir eficazmente los grupos químicos a partir de las diferencias en cuanto a su contenido en $\mathrm{CaO}$. Sin embargo, hemos utilizado el tercer componente (figura I lb) para caracterizar con mayor precisión el grupo CDA3, atraído por - C3 y por lo tanto con una riqueza mayor de las fases $\ln (\mathrm{K} 2 \mathrm{O} /$ $\left.\mathrm{Al}_{2} \mathrm{O}_{3}\right)$ y $\ln \left(\mathrm{Ni} / \mathrm{Al}_{2} \mathrm{O}_{3}\right)$.

De esta forma, el grupo CDAI aparece como un grupo no calcáreo o muy poco calcáreo, con contenidos de $\mathrm{CaO}$ que no superan el $2 \%$, a excepción de algunas muestras aisladas. Por su parte, el grupo CDA2 presenta muestras con un contenido algo superior de $\mathrm{CAO}$, entre el $2.25 \%$ a $9.36 \%$, con algunas excepciones por debajo del $2 \%$ o por encima de $10 \%$. Y, por último, el grupo CDA3, que corresponde a la fase antigua del taller, se caracteriza por su bajo contenido en $\mathrm{CaO}$, aunque con valores más elevados de lo habitual de $\mathrm{Fe}_{2} \mathrm{O}_{3}$ y $\mathrm{Ni}$. Sin embargo, la existencia de muestras con una composición química similar no implica obviamente que la forma en que los elementos se combinan origine siempre el mismo tipo de minerales, ni mucho menos que procedan de los mismos componentes petrográficos. De forma que estos resultados deben ser complementados por la caracterización petrográfica de los individuos a partir de su observación mediante microscopio polarizador.
La observación petrográfica presenta ciertos límites a la hora de determinar las asociaciones minerales observadas en cada muestra, ya que la composición mineralógica de la matriz no es detectable a microscopio. De forma que los análisis por DRX, también, han resultado aclaratorios al discriminar diversas fábricas de cocción a partir de los tres grupos químicos originales. Así pues, dentro de los grupos químicos definidos anteriormente, ciertamente heterogéneos, se originan agrupaciones menores, que aportan mayor precisión y resuelven otros interrogantes planteados en torno al proceso de producción. La tabla que adjuntamos esquematiza a grandes rasgos la clasificación general por grupos y fábricas en función de las tres técnicas analíticas aplicadas a la muestra (figura 12).

El análisis petrográfico de las muestras, que ha seguido la propuesta metodológica de I. Whitbread, ha permitido discriminar claramente cuatro grupos petrográficos y cinco subgrupos (WHITBREAD, 1989 Y 1995). Cabe recordar que por grupo de fábrica entendemos al conjunto de muestras que presentan una composición muy similar en lo que concierne a la naturaleza, abundancia y apariencia de las inclusiones, la matriz y la porosidad. El grupo incluye, en consecuencia, muestras formadas a partir de una misma materia prima y una técnica de preparación de la pasta similar, aunque admite ligeras variaciones del tipo color, ya que dicha alteración es sutil y no siempre responde a una variación sustancial en las técnicas utilizadas. Por el contrario, el subgrupo es una variable del grupo de fábrica, bien definida y separada del grupo principal, que puede presentar ligeras variaciones en la preparación de la pasta o bien ligeras alteraciones de tipo natural en la materia prima utilizada.

El grupo CDA I se caracteriza por una pasta grosera, con abundantes inclusiones -alrededor del 30\% del total de la composición- de una roca ígnea ácida, presumiblemente granitoide o granodiorita, que carece de cualquier otro tipo de inclusión no relacionada directamente con dichas formaciones. De forma que, al margen de los pequeños fragmentos claramente identificables de esta roca, el conjunto presenta una 
amalgama de inclusiones compuestas mayoritariamente por cuarzos, feldespatos y micas, con especial presencia de biotita, que responden a las inclusiones propias de dicha formación rocosa. Este tipo de pasta constituye la materia prima utilizada por el alfar, al menos durante las fases finales de producción, y es común, además, a todos los grupos petrográficos hallados. De esta forma, los grupos restantes se caracterizan específicamente a partir de las inclusiones ajenas al granitoide que, de forma ocasional o intencionada, pueden aparecer junto a la asociación principal (figura 13).

Por su parte, las variaciones que reflejan los subgrupos 2, 3, 4 y 5 parecen ser contaminaciones leves de tipo natural, ya que no alteran significativamente la composición de la pasta, aunque explican en cierta forma la heterogeneidad del grupo composicional CDA I. El subgrupo 2 presenta, por ejemplo, una proporción variable según la muestra de unas inclusiones metamórficas de una filita no excesivamente gruesa o en algunos casos de tránsito pizarra-filita, mientras que en el subgrupo 3 se detectan algunas inclusiones escasas de un componente calcáreo de tipo micrita que no altera significativamente la composición inicial de la pasta.

Los individuos del subgrupo 4 presentan simultáneamente las inclusiones características de los subgrupos 2 y 3 , en proporciones muy similares y con las mismas características. El subgrupo 5 tiene la particularidad de presentar algunos fragmentos de una roca sedimentaria, de origen detrítico y composición cuarzosa, con un porcentaje elevado de matriz, hecho que nos lleva a pensar en una posible grauvaca, también en una proporción reducida respecto del total de inclusiones relacionadas con el granitoide. Las inclusiones de calcita y filita que nos permitían diferenciar otros subgrupos no son significativas en este caso y no aparecen en todas las muestras.

El grupo composicional CDA2 presenta variaciones más significativas en relación a su caracterización petrográfica, aspecto que no debe sorprender si tenemos en cuenta que su heterogeneidad es bastante mayor en comparación con el grupo CDAI. En este segundo conjunto distinguimos dos grupos de fábrica y un subgrupo. Por un lado, el grupo 6 que presenta unas inclusiones muy características de tipo arcilloso, en algunos casos con laminación y en otros con algunas inclusiones cuarzosas, en estrecha relación con una matriz en donde abundan las características texturales como bandas, vetas o remolinos (WHITBREAD 1986; CUOMO DI CAPRIO,VAUGHAN, 1993).

Por otro lado, el grupo 7 ofrece junto a los elementos ordinarios frecuentes inclusiones de micrita, de tamaño considerable, mucho más abundantes sin duda que las reconocidas en los subgrupos 3 y 4 , ofreciendo características texturales peculiares como las descritas para el grupo 6. Finalmente, el subgrupo 8, se relaciona con los precedentes, puesto que aúna en los mismos individuos la presencia de ambos tipos de inclusiones, aunque el porcentaje de micrita puede llegar a ser ligeramente inferior. Dichas características petrográficas explicarían en parte el contenido en $\mathrm{CaO}$ más elevado del conjunto CDA2, así como su mayor heterogeneidad.

El grupo CDA3, mucho más reducido y homogéneo, corresponde con un único grupo de fábrica que parece distinguirse de los demás, desde el punto de vista estrictamente petrográfico, más por su textura que por sus inclusiones (grupo 9). Nos referimos a individuos con un porcentaje de inclusiones algo menor que en los casos anteriores y de dimensiones claramente inferiores. El tamaño menor de la fracción dificulta lógicamente la detección de fragmentos claros de granitoide, aunque la proporción de las inclusiones relacionadas con dicha roca se mantienen igual que en los grupos anteriores. Aun así, las muestras presentan una matriz mucho más homogénea y de coloración más oscura que en el resto de grupos.

Los resultados obtenidos por DRX permiten definir varias fábricas en función de los minerales detectados en cada caso. Si retomamos la tabla clasificatoria, podremos advertir como algunas de las fábricas son claramente minoritarias, mientras que otras presentan una cierta entidad al incluir un número de individuos (entre 10 y 15) significativo (figura 12). Los grupos se distinguen fundamentalmente 
por la presencia o ausencia de minerales de alta y baja temperatura respectivamente, por lo que las fábricas definidas en función de distintas fases minerales aparecen ordenadas para cada grupo composicional de menor a mayor temperatura.

De esta forma, detectamos en todos los individuos una mineralogía que se mantiene estable en todas las fases formada por cuarzo, plagioclasas y feldespato potásico, junto con ciertos minerales que se descomponen para formar otros nuevos. La materia prima utilizada es una arcilla ilítica de origen granítico. De hecho, muchas de las fábricas contienen ilita en mayor o menor proporción, lo que indica una temperatura de cocción que no ha llegado a superar los $950^{\circ} \mathrm{C}$. Sin embargo, es muy frecuente la presencia de hercinita en buena parte de las muestras, lo que avalaría el uso de temperaturas más elevadas (figura 14). Cabe recordar que la hercinita es un mineral que se forma en ambientes reductores a temperaturas relativamente elevadas $\left(950-1000^{\circ} \mathrm{C}\right)$, cuando ya se han superado las fases de estabilidad de la ilita y que, en nuestro caso, aparece ocasionalmente junto con la mulita en el grupo no calcáreo (CDA I). Una referencia que nos indicaría que muchas de estas muestras han llegado a alcanzar los $1050^{\circ} \mathrm{C}$.

Un planteamiento similar parece reproducirse en el grupo algo más calcáreo (CDA2), salvo que en este caso, no se registra ninguna fábrica con presencia de mulita. En las muestras cocidas a mayor temperatura se detecta hercinita junto con un componente calcáreo, mientras que en la fábrica mayoritaria cocida a menor temperatura abunda la ilita y también se constata la presencia de hematites en relación con las inclusiones arcillosas.

\section{La interpretación de los resultados}

Los análisis practicados a los materiales cerámicos han permitido resolver no pocos interrogantes que se han venido planteando en relación a los medios y tecnología de producción aplicada en este alfar medieval. Una de las cuestiones que suscitaba nuestro interés, era determinar si había existido algún procedimien- to previo de decantación para la preparación de la materia prima. Se trataba de conocer, además, si los desgrasantes o inclusiones que aparecen en la matriz podrían ser considerados como el resultado de una combinación de origen natural o, por el contrario, respondían a una adición voluntaria del artesano a efectos de obtener la plasticidad y características deseadas. Aspectos que a fin de cuentas afectan tanto a los procedimientos, como a la propia organización del área artesanal.

Los análisis microscópicos de las inclusiones nos hicieron descartar pronto la existencia de procesos de decantación, ante las características que ofrecían la mayor parte de los desgrasantes. Cabe tener en cuenta que el alfarero debe triturar, por lo general, la materia que utilizará como desgrasante antes de incorporarla a la base arcillosa. La preparación del desgrasante produce fragmentos muy angulosos debido a su fractura reciente $y$, por lo general, bien sorteados, ya que los fragmentos de mayores dimensiones se reducen para asimilarlos al conjunto. De esta forma, el resultado final será un grano más o menos fino, pero homogéneo y de dimensiones regulares. Ello da origen, por lo general, a fracciones unimodales, bimodales o polimodales en función del tipo de desgrasante añadido.

En el caso de Cabrera, la presencia de inclusiones pobremente sorteadas y de tipo muy heterogéneo nos obliga a descartar la posibilidad de que los desgrasantes procedan de una adición voluntaria, a la vez que nos induce a considerarlos como inclusiones naturales presentes en la materia prima. La heterogeneidad, que se registra tanto en los componentes graníticos principales (fragmentos de granodiorita, cuarzos, feldespatos y biotitas), como en lo que parecen ser contaminaciones (filita, pequeñas proporciones de calcita 0 grauvaca), nos indica que la arcilla no ha sido decantada, por lo que cabe suponer que se ha operado sobre una materia arcillosa que no ha recibido ningún tratamiento de depuración específico. Las inclusiones de filita, calcita o grauvaca, también, deben considerarse como contaminaciones naturales, ya que la proporción irregular en que aparecen, así como su sorteo, no permite 
deducir en ningún caso que hayan sido añadidas de forma voluntaria.

La situación parece ser diferente en relación al grupo CDA2. En este caso, la base o materia prima con inclusiones naturales aporta dos componentes, que consideramos, añadidos. Se trata, por un lado, de las inclusiones de tipo arcilloso que definen el grupo petrográfico 6 y, por otro, de la presencia de calcita en proporciones claramente superiores a lo habitual. Si atendemos a que tanto las inclusiones arcillosas, como las calcáreas, no son habituales en el conjunto y que cuando aparecen en las muestras, lo hacen en proporciones importantes y en contextos muy concretos, habremos de considerar que se trata de elementos claramente añadidos.

En tal sentido, cabe preguntarse qué finalidad ha podido tener esta adición complementaria y en qué momento se inicia dicha práctica. La presencia de estos componentes parece estar relacionada con las características texturales de la matriz, particularmente reconocibles en el caso de las inclusiones arcillosas. Dichas inclusiones en su estado no plástico parecen deshacerse en contacto con la pasta húmeda, lo que origina la presencia de vetas y remolinos que responderían a materiales que no han terminado de amalgamarse con la pasta base. Ni la composición de estos elementos ni el resultado que producen en la pasta nos permite suponer que hayan sido añadidos para mejorar las características técnicas del producto resultante. De modo que cabe aventurar que el objetivo de aquella adición tal vez se relacione con la necesidad de ajustar la plasticidad de una pasta muy grosera y difícil de modelar, en un momento en que se hubiera perdido la soltura y destreza de otros tiempos.

Por otro lado, la gran cantidad de inclusiones naturales nos permite aportar una respuesta clara acerca de la proveniencia de la materia prima empleada. A través de estos elementos es posible determinar dónde se encontraba la barrera o área de obtención de la arcilla que abastece el taller. Si observamos con detenimiento el mapa geológico de la zona, advertimos que el sector de granodiorita que rodea al alfar es susceptible de aportar las inclusiones mayoritarias de la producción, por lo que necesariamente debemos encontrar en ese ámbito una fuente de arcilla próxima que pueda presentar dichas inclusiones (figura 15). Además, las pronunciadas aristas de los desgrasantes confirman que estos elementos no han sufrido un proceso de transporte demasiado largo antes de su sedimentación. Por lo que todo apunta a que la materia prima haya sido obtenida en algún punto cercano, probablemente en el meandro del río, ya que la terraza fluvial permite una zona de sedimentación, rica en arcillas y arenas. Dicho origen parece explicar de forma razonable la presencia de inclusiones metamórficas en buena parte de las muestras analizadas, ya que aquéllas habrían sido arrastradas por el río desde la formación antigua de pizarras arenosas.

Sin embargo, no podemos precisar cuál ha podido ser la procedencia de las inclusiones arcillosas añadidas en las fases tardías. El sector registra algunos depósitos de arcillas terciarias, aunque alejadas del centro productor. En una posición más cercana se aprecian, también, otros sedimentos arcillosos que se presentan en frecuente alternancia con areniscas. Pero ni un caso ni otro ofrecen suficiente fiabilidad para determinar la proveniencia de estas inclusiones. Por el contrario, el componente calcáreo que se observa en las muestras en una proporción significativa, es, en la gran mayoría de casos, micrita, en ocasiones con alguna inclusión accidental de cuarzo, por lo que presumiblemente ha sido obtenida del propio travertino.

El estudio petrográfico ha resultado muy revelador con relación a las técnicas de modelado. La posición de las inclusiones nos permite identificar en un número elevado de muestras, la presencia de una microestructura característica, que corresponde a piezas urdidas o modeladas "a colombín" o "a rollo" (WOODS, 1985, WHITBREAD, 1996). El alfarero, al seguir este procedimiento, modela de forma individual la serie de rollos que superpuestos acabarán por constituir las paredes del vaso. La presión ejercida por el artesano a la hora de modelar dichos rollos determina que las inclusiones de mayores dimensiones tiendan a colocarse en paralelo a las paredes de aquellos elementos. De modo 
que, si practicamos una sección transversal en uno de los rollos, hallaremos en su interior una disposición de las inclusiones en forma de círculo. Al modelar el vaso, el alfarero desdibuja la estructura de estos rollos mediante el alisado de las paredes, pero la fuerza de sus manos no es suficiente para destruir la microestructura interna de los rollos. De forma que, al realizar una sección vertical del vaso acabado, es posible detectar la serie de testimonios circulares formadas por los desgrasantes que corresponden en cada caso a la microestructura relicta de un rollo (figura |6).

El procedimiento habitual de trabajo pudo seguir las pautas siguientes: la arcilla, con abundantes inclusiones naturales, obtenida con probabilidad en algún sector del meandro del río Anoia, era trasladada hasta el alfar para su utilización. Los limos arcillosos debieron recibir una somera preparación mediante la retirada manual de impurezas e inclusiones groseras, pasando a ser golpeada con percutores para igualar sus componentes. Una vez reposada, la materia base podía ser utilizada en la elaboración de las piezas. En este caso, la torneta juega un papel de soporte al urdido, de modo que su principal actividad se corresponde con el alisado de las superficies y el torneado regular de los bordes de unas piezas que han sido preferentemente urdidas de forma manual. Las propias características de una materia arcillosa gruesa, con inclusiones de grandes dimensiones, muy angulosas y con rebordes cortantes sugieren descartar el torneado como el medio más idóneo de modelado. Sin embargo, es posible que en la última etapa del taller, cuando los productos se revelan algo más toscos e irregulares, se hubiera buscado tal vez alguna fórmula alternativa para aumentar la ductilidad y maleabilidad de la pasta y facilitar el trabajo de modelado.

Por otro lado, poco podemos añadir en relación al nivel de temperaturas de cocción deseado, ya que los testares recogen producciones inservibles procedentes de cocciones ordinarias y defectuosas. Al no poder diferenciar unas de otras, sólo podemos aventurarnos a estimar un rango de temperaturas de cocción amplio que oscila entre los $800-1000^{\circ} \mathrm{C}$. Dichas tempera- turas son sorprendentemente muy elevadas, si tenemos en cuenta que, teóricamente, las producciones habituales de cerámica gris de tipo culinario no suelen alcanzar un rango de temperaturas tan elevado (PICON, 1995). La resistencia al choque térmico viene dada por la capacidad de la cerámica de soportar sin resquebrajarse las microfracturas que se originan en el recipiente a causa de su baja conductividad al ser llevado al fuego. Durante los primeros minutos de utilización, la diferencia de temperatura entre las paredes externa e interna del vaso puede llegar a romper el recipiente si su estructura interna no es capaz de soportar dicho choque.

Al cocer las piezas a temperaturas bajas, entre $600-800^{\circ} \mathrm{C}$, se mantiene la microestructura laminar originaria de las arcillas, que confiere a los vasos una tenacidad mayor en detrimento de la dureza, que permite absorber dichas fracturas. A medida que la temperatura de cocción aumenta y la microestructura laminar de la arcilla se pierde, el vaso perderá su capacidad para absorber las microfracturas, a no ser que se incorpore otros elementos para realizar dicha función, este es el caso, por ejemplo, de las inclusiones de cuarzo.

De esta forma, durante la cocción de la pieza el cuarzo se dilata durante la fase de calentamiento hasta alcanzar la temperatura máxima, por lo que la matriz deberá acomodarse a las nuevas dimensiones de los granos de cuarzo (KILIKOGLOU et alii, 1995). Durante la fase de enfriamiento, el cuarzo recuperará sus dimensiones iniciales, pero sin que la matriz modifique ya su microestructura, porque tras la cocción deviene inalterable. Así, se origina alrededor de las inclusiones de cuarzo una porosidad que absorberá las microfracturas y garantizará la resistencia de la pieza durante el choque térmico (figura 17). La arcilla de Cabrera d'Anoia no requiere una decantación, ya que las inclusiones, en su mayoría, cuarzosas que aporta, son adecuadas para producir con éxito una cerámica culinaria a las temperaturas de cocción que hemos enunciado.

Por otro lado, una temperatura de cocción elevada garantiza una mayor resistencia 
al choque mecánico, que confiere un valor añadido a esta producción culinaria. De modo que todo parece indicar que los alfareros de Cabrera llegaron a conseguir una producción a bajo coste, que cumplía con creces su función culinaria y presentaba, además, una resistencia destacable a la tracción y al impacto, acaso la única forma posible de asegurar el éxito de estas manufacturas.

\section{CONCLUSIONES}

Las investigaciones arqueológicas realizadas sobre el conjunto artesanal de Cabrera d'Anoia han permitido recomponer a grandes líneas la peculiar organización de este alfar medieval, mostrando las características de estos espacios de trabajo que adaptan su actividad a un modelo de producción en gruta. A pesar de las profundas alteraciones sufridas por el yacimiento y de la naturaleza tenue de muchas evidencias, hemos podido advertir las estrategias que emplea la actividad alfarera en su adaptación a un espacio aparentemente poco propicio, así como reconocer las directrices de un modelo productivo caracterizado por la constante transformación del espacio artesanal.

Los procesos geomorfológicos han tenido un papel destacado en la evolución del emplazamiento y del espacio artesanal. Los factores de índole antrópica han afectado de forma sustancial a la dinámica del ciclo geográfico, desencadenando una transformación acelerada y continua del paisaje artesanal. Las condiciones del terreno y las necesidades productivas obligaron a los alfareros a mantener su actividad inserta dentro de un proceso de cambio continuo que les obligó a desplazar, con frecuencia, tanto las estructuras de cocción como la ubicación de los obradores. La transformación del espacio artesanal muestra que han existido algunas pautas para aprovechar del modo efectivo las limitaciones del espacio de trabajo, así se deduce, por ejemplo, de la progresión de las estructuras de cocción y de la necesidad de amortizar con rapidez las estructuras obsoletas.
Las cavidades rupestres han permitido ubicar las áreas de obrador, mientras en las proximidades se excavaban y erigían las estructuras de cocción. Unas estructuras, que a pesar de su aparente robustez, ofrecen una vida útil limitada, ya que no están exentas de una rápida degradación ante las tensiones sucesivas que deberán afrontar en cada cocción. Las reparaciones continuas de los alfareros no logran paliar el problema, de modo que es inevitable entrar en un ciclo periódico de sustitución de las estructuras de cocción. Un proceso necesario para el desarrollo de las actividades artesanales, pero que implica el consumo paulatino del espacio disponible hasta agotar la disponibilidad del sector. Una vez agotadas las posibilidades del área, la actividad artesanal se habrá de desplazar hacia un nuevo emplazamiento, donde reconstruirá el área de obrador y reabrirá una nueva batería de hornos sobre la línea de la plataforma. De esta forma, la actividad alfarera se desarrolla ante un escenario que se transforma de forma continua.

La densidad de las instalaciones y el volumen de materiales recuperados parecen indicar que se trata de un centro productor de prolongada actividad. Su producción esencial parece basarse en la elaboración de ollas, en sus diversas versiones, aunque se documenta también una reducida proporción de cazuelas, tapaderas y diversos recipientes para líquidos, así como lebrillos y otros útiles de gran formato. Se trata de una vajilla de uso culinario con formas que perduran sin grandes variaciones a lo largo del tiempo.

Esta producción ofrece, por lo general, pastas groseras, con inclusiones de grandes dimensiones, que han sido modelada combinando las técnicas manuales de urdido y el uso específico de la torneta. No presentan acabados a excepción de un ligero alisado de la cara externa, que puede venir acompañado por algún tipo de decoración incisa que en cualquier caso se dispone sobre la parte superior de la panza. La producción adopta los procesos y técnicas de cocción en atmósfera reductora, por lo que las piezas presentan coloraciones grises que abarcan un abanico entre los tonos claros y el gris más plomizo. 
Se advierte una cierta monotonía morfológica de la producción que no permite diferenciar la existencia de una sucesión tipológica clara a lo largo de todas las etapas productivas que hemos podido documentar. A pesar de los acusados rasgos de continuidad de esta producción, se detectan sutiles variaciones morfológicas que son identificables, básicamente, a partir del examen exclusivo de los bordes de la forma tipo olla, por causa de la extrema fragmentación del conjunto estudiado. De este modo, a medida que avanza el tiempo, vemos como la producción presenta un grado de elaboración mayor que pasa de los labios simples a las formas de labio compuesto que parecen denotar una gran destreza en el modelado de las formas. Con todo, la elaboración sufrirá un proceso de simplificación que se hace perceptible ya en el tránsito al siglo XIV y que se acentuará aún en mayor medida hacia la fase final del alfar.

Estas producciones han sido elaboradas a partir de una arcilla ilítica, muy grosera, de origen granítico que presenta numerosas inclusiones de granodiorita, ya sea como fragmentos de roca claramente identificables o como asociaciones minerales formadas por inclusiones de cuarzos, feldespatos y fragmentos micáceos. Las características petrográficas del material nos permiten confirmar que no ha existido adicción voluntaria de desgrasantes, ya que las inclusiones graníticas y metamórficas que contiene forman parte de los componentes naturales que aporta la materia primaria arcillosa.

De este modo, los alfareros emplean una arcilla que no necesitan decantar ni depurar en exceso, ya que la abundancia de inclusiones naturales que aporta, son suficientes para conseguir una textura suelta, capaz de absorber las tensiones que produce el choque térmico y permitir su utilización culinaria. El resultado debió de convertir a las piezas de Cabrera d'Anoia en un producto ciertamente apreciado en la zona, por lo que no es extraño que su actividad se prolongara en el tiempo. No será hasta la última etapa del alfar, cuando detectemos la adicción voluntaria de algunos componentes, que parecen destinados a aumentar la plasticidad de la materia prima, tal vez para compensar la disminución probable de la pericia artesanal de otros tiempos.

Las formas elaboradas en este alfar han sido cocidas en un ambiente altamente reductor, a temperaturas que en la mayoría de casos debieron de superar los $800^{\circ} \mathrm{C}$, sin que ello suponga un problema de cara a su utilización culinaria (HEIN et alii, 2008). En cualquier caso, esta referencia es significativa en el caso de las producciones medievales de tipo reductor, por lo que deberá cotejarse necesariamente con otras producciones similares. El análisis extensivo podrá responder a las nuevas interrogantes surgidas en torno al rango de temperaturas y su adecuación a las producciones de uso culinario.

Del mismo modo, el estudio arqueométrico de otras producciones culinarias seguramente aportará nuevas informaciones sobre la procedencia de la materia prima utilizada en su caso, así como sobre si la carencia de procesos de decantación de las arcillas ha sido generalizada en la elaboración de estas manufacturas. En cualquier caso, los trabajos de caracterización de la producción de Cabrera d'Anoia han logrado recomponer una colección de referencia a partir de la cual esperamos poder determinar el radio de distribución de las producciones de este alfar, así como avanzar de forma significativa en la determinación de los procesos productivos que sustentan la elaboración de cerámicas culinarias en época medieval.

\section{BIBLIOGRAFÍA}

AMOURIC, H.; THIRIOT, J.; VAYSSETTES, J.L. ( 1995): “Ateliers en grotte: apport contrasté des sources écrites et des dones de terrain". Actas das I Jornadas de Cerâmica Medieval e Pós-Medieval, métodos e resultados para o seu estudo (1 992), Tondela, 1995, pp. 263-269.

CUOMO DI CAPRIO, N.; VAUGHAN, S. J. (1993): "An experimental study in distinguishing grog (chamotte) from argillaceous inclusions in ceramic thin sections". Archaeomaterials, 7, 1993, pp. 21-40.

HEIN, A.; MÜLLER, N.; DAY, P. M.; KILIKOGLOU,V. (2008):

"Thermal conductivity of archaeological ceramics: the effect of inclusions, porosity and firing temperature". Thermochimica Acta, 480, 2008, pp. 35-42. 
KILIKOGLOU,V:;VEKINIS, G.; MANIATIS,Y. (1995): "Toughening of ceramic earthenwares by quartz inclusions: an ancient art revisited". Acta Metallurgica et Materialia. 43(8), 1995, pp. 2959-2965.

LEENHARDT, M. ; PADILLA, J.I. ; THIRIOT, J.; VILA, J.M. (1993): "Primers resultats dels treballs al taller medieval de ceràmica grisa de Cabrera d'Anoia", Estrat. Revista d'Arqueologia , Prehistòria i Història Antiga, 6, 1993, pp. I 5 I 177.

LEENHARDT, M. ; PADILLA, J.I. ; THIRIOT, J. ( 1995): "Organisation spatiale de l'atelier de poitiers de Cabrera d'Anoia (Catalogne)". Vème colloque international sur la céramique médiévale en Méditerranée Occidentale (Rabat, 1/-17 novembre 1991), Rabat, 1995, pp. 58-63.

LÓPEZ MULLOR, A. ; NIETO, F.J. ( 1979): "Hornos de cerámica gris medieval en el castell de Cabrera d'Anoia". Informació arqueològica, 30 (maig-agost 1979), 1979, pp. |54-|6|.

PADILLA, J.I. (1984): "Contribución al estudio de las cerámicas grises catalanas de época medieval: el taller, los hornos y la producción de Casampons", Ceràmica grisa i terissa popular de la Catalunya Medieval. Acta Mediaevalia, annex 2, Barcelona, 1984, pp. 99-143.

PADILLA, J.I.;VILA. J.M. ( 1997): "El tester 374-B de Cabrera d'Anoia. Anàlisi d'una fase de la producció d'aquest centre artesanal", Ceràmica medieval catalana. El monument, document, Quaderns científics i tècnics, 9, Barcelona, 1997. pp. |43-158.

PADILLA, J.ı; VILA, J.M. ( 1998): “Últimas intervenciones en el alfar medieval de Cabrera d'Anoia. Barcelona". Actas das 2as Jornadas de Cerâmica Medieval e Pos-Medieval. Tondela (Portugal), 1995, Tondela, 1998, pp. 91-99.

PADILLA, J.I.; THIRIOT, J.; EVIN, J.; MESTRES, J. (1999): "Datations par le radiocarbone des ateliers de potiers médiévaux de Cabrera d'Anoia en Catalogne". In J. Evin et alii. Actes du 3ème congrès international d'archéologie et 14C. Lyon, 1998. Revue d'Archéometrie suppl. et Mémoires de la Société préhistorique Française. n. XXVI, pp. 419-423.

PADILLA, J. I.; ÁLVARO, K:; TRAVÉ, E. (2008): "Un modelo de producción en gruta: el Alfar de Cabrera d'Anoia, Barcelona". Munibe (Antropologia-Arkeologia), 59, San Sebastián, 2008, pp 25I-272.
PICON, M. (1995): "Grises et grises: quelques réflexions sur les céramiques cuites en mode B.", Actas das $1^{a}$ Jornadas de Cerâmica Medieval e Pós-Medieval, métodos e resultados para o seu estudo (1992), Tondela, 1995, pp. 283-287.

ROMANÍ, A. (1997): "Paletnologia de la Comarca de Capellades". Butlletí del Centre Excursionista de Catalunya, 27I, 1917, pp. 197-206.

THIRIOT,J. (1980):" "Stratigraphie dans un four de potier du XII siècle à Saint-Victor-des-Oules (Gard)", La céramique médiévale en Méditerranée occidentale, X-XV siècles, (Valbonne, I I- 44 septembre 1978), París, 1980, pp. 457 i ss.

THIRIOT, J. (1986): Les ateliers médiévaux de poterie grise en Uzège et dans le Bas-Rhône: Premières recherches de terrain. Documents d'Archéologie Française. 7. París: Ed. de la Maison des Sciences de l'Homme.

TRAVÉ, E. (2009): Producció i distribució d'una terrisseria medieval: Cabrera d'Anoia. (http://www.tesisenxarxa.net/ TDX-0 I I 2 I I 0- I | | 9 |7). ISBN: 978-84-692-9975-3. Universitat de Barcelona.

WHITBREAD, I.K. (1986): "The characterization of argillaceous inclusions in ceramic thin Thin Sections." Archaeometry, 28, 1986, pp 79-88.

WHITBREAD, I.K. (1989): "A proposal for the systematic description of thin sections towards the study of ancient ceramic technology. In: Maniatis, Y. (ed.) Archaeometry: Proceedings of the 25th International Symposium. Elsevier, Amsterdam, 1989, pp. 127-138.

WHITBREAD, I.K. (1995): "The collection, processing and interpretation of petrographic data". In Greek transport amphorae, a petrological and archeological study. Fitch Laboratory Occasional Paper, 4. Appendix 3. Oxford, 1995, pp. 365-396.

WHITBREAD, I.K. (I 996): "Detection and Interpretation of Preferred Orientation in Ceramic Thin Sections", Proceeding of the 2nd Symposium of the Hellenic Archaeometric Society (26-28 March 1993) 4, 1996, pp. I3-425.

WOODS, A. (1985): "An introductory note on the use of tangential thin sections for distinguishing between wheel-thrown and coil/ring built vessels". Bulletin of the Experimental Firing Group, 3, 1985, pp. I I0-1 I 4. 


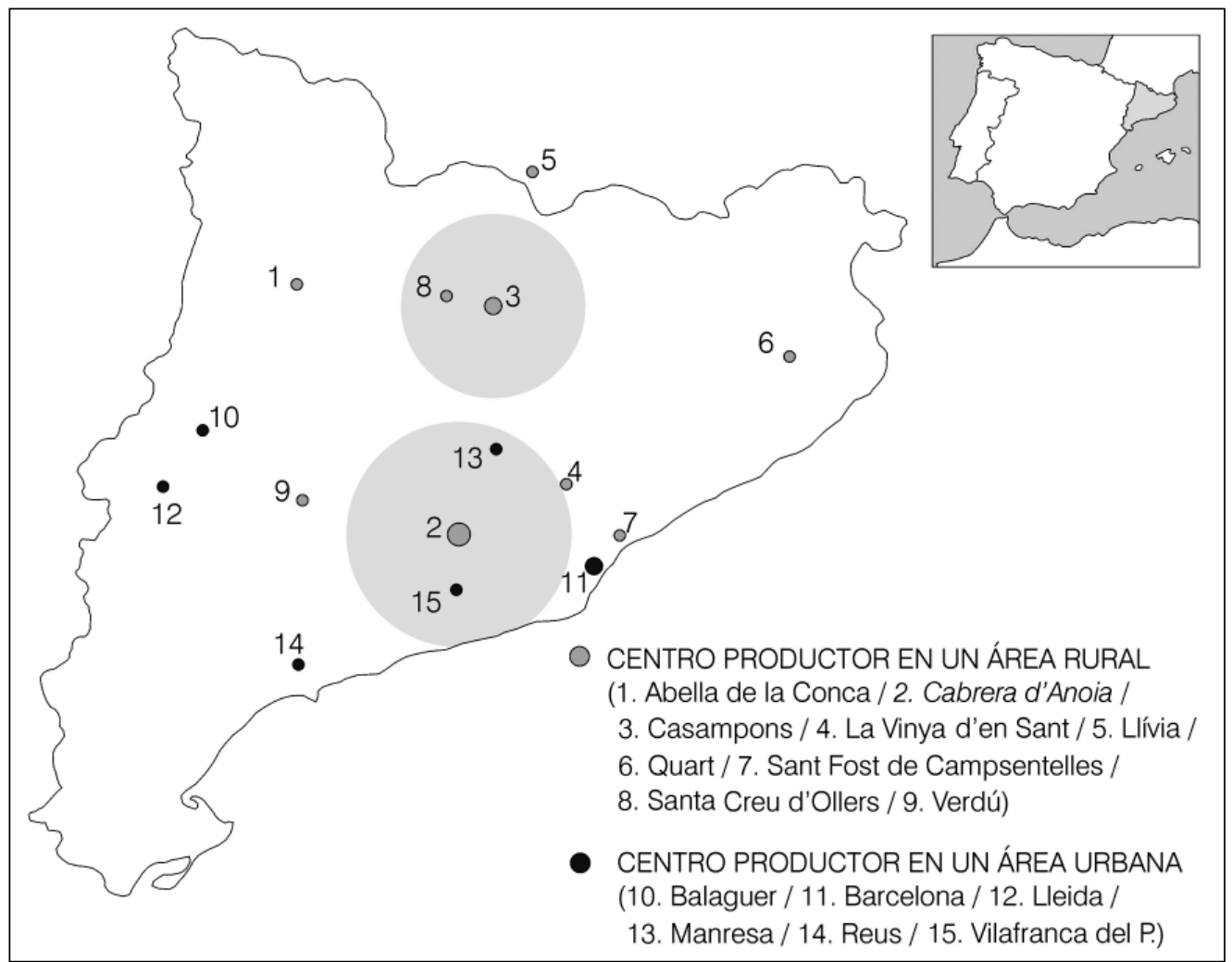

Figura I: Distribución territorial de los principales centros productores catalanes entre los que se incluye el alfar de Cabrera d’Anoia, cuya área de distribución pudo haber superado los $60 \mathrm{~km}$.

Figura 2: Niveles geológicos que posibilitan la ocupación en gruta en el yacimiento de Cabrera. En la parte superior se observa la cubierta de travertino sobre los niveles graníticos donde se forman las cuevas.

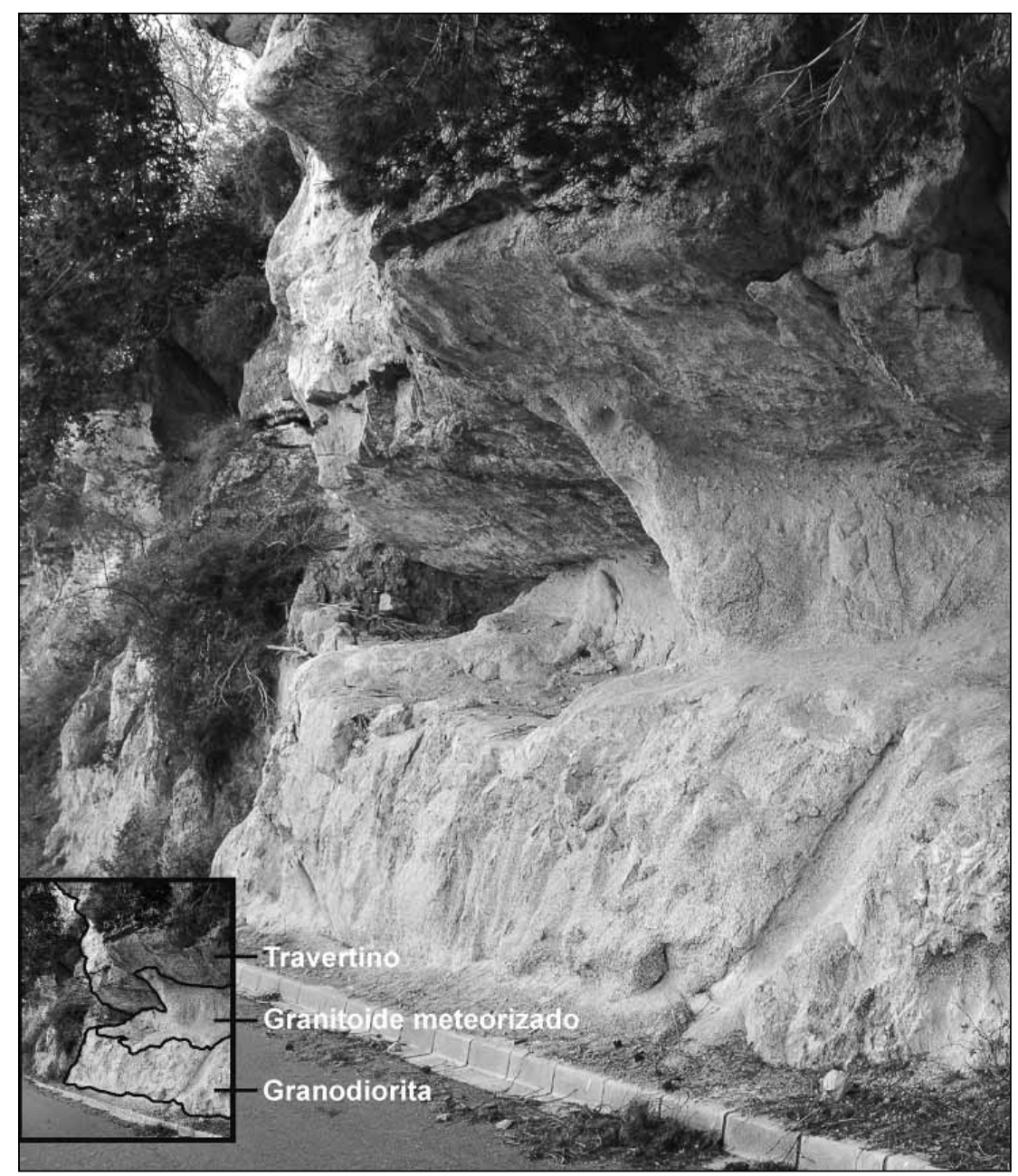




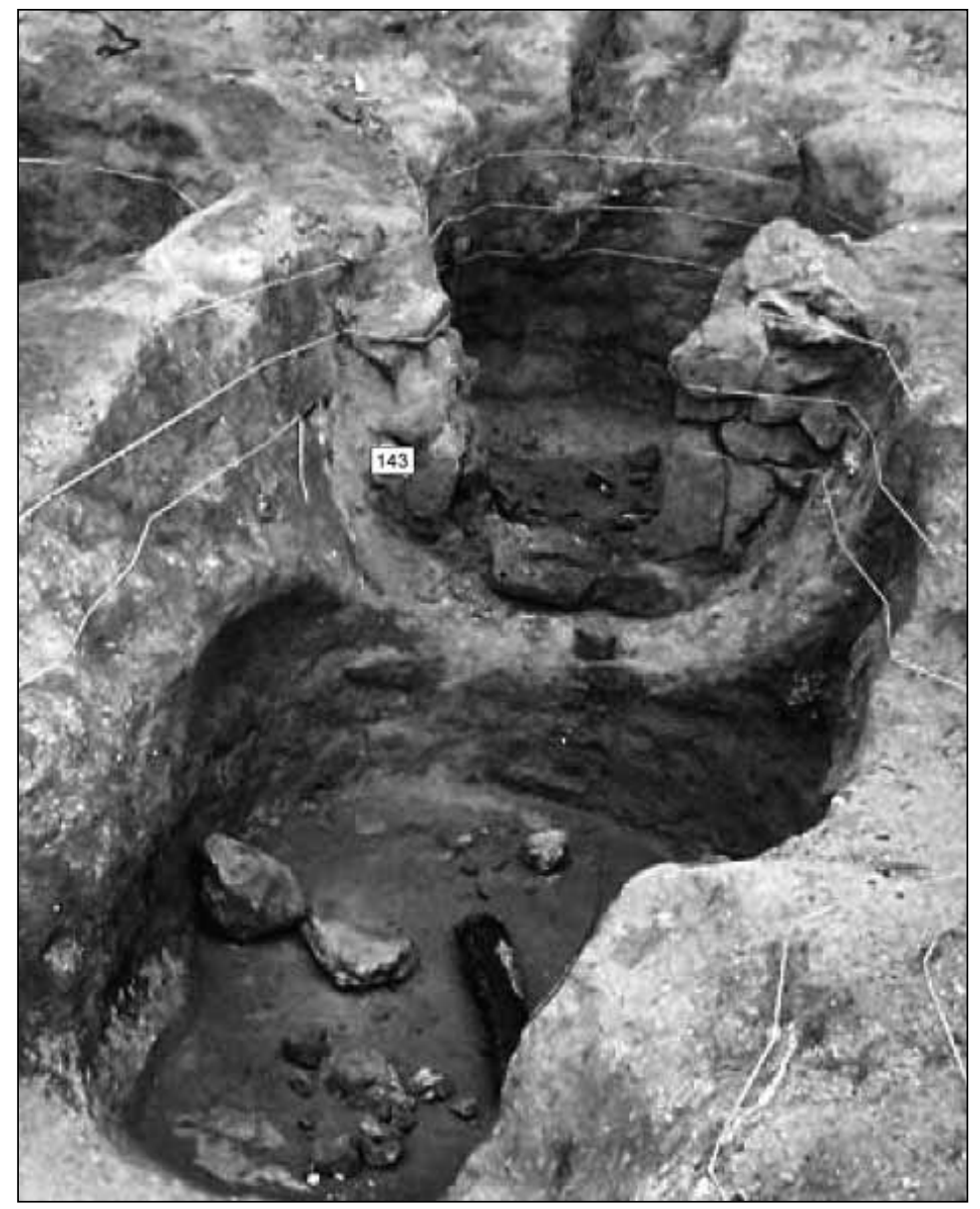

Figura 3: Vista frontal de la alineación formada por los hornos CDA-99-N (al frente de la imagen) y CDA-99-F (Al fondo), en donde se aprecia de forma clara la reutilización de estructuras obsoletas.

Figura 4: Horno A. Representación en planta (a), y sección longitudinal de la cámara de fuego (b), en donde aparecen representados los restos de la parrilla hundida y los arcos de reparación.
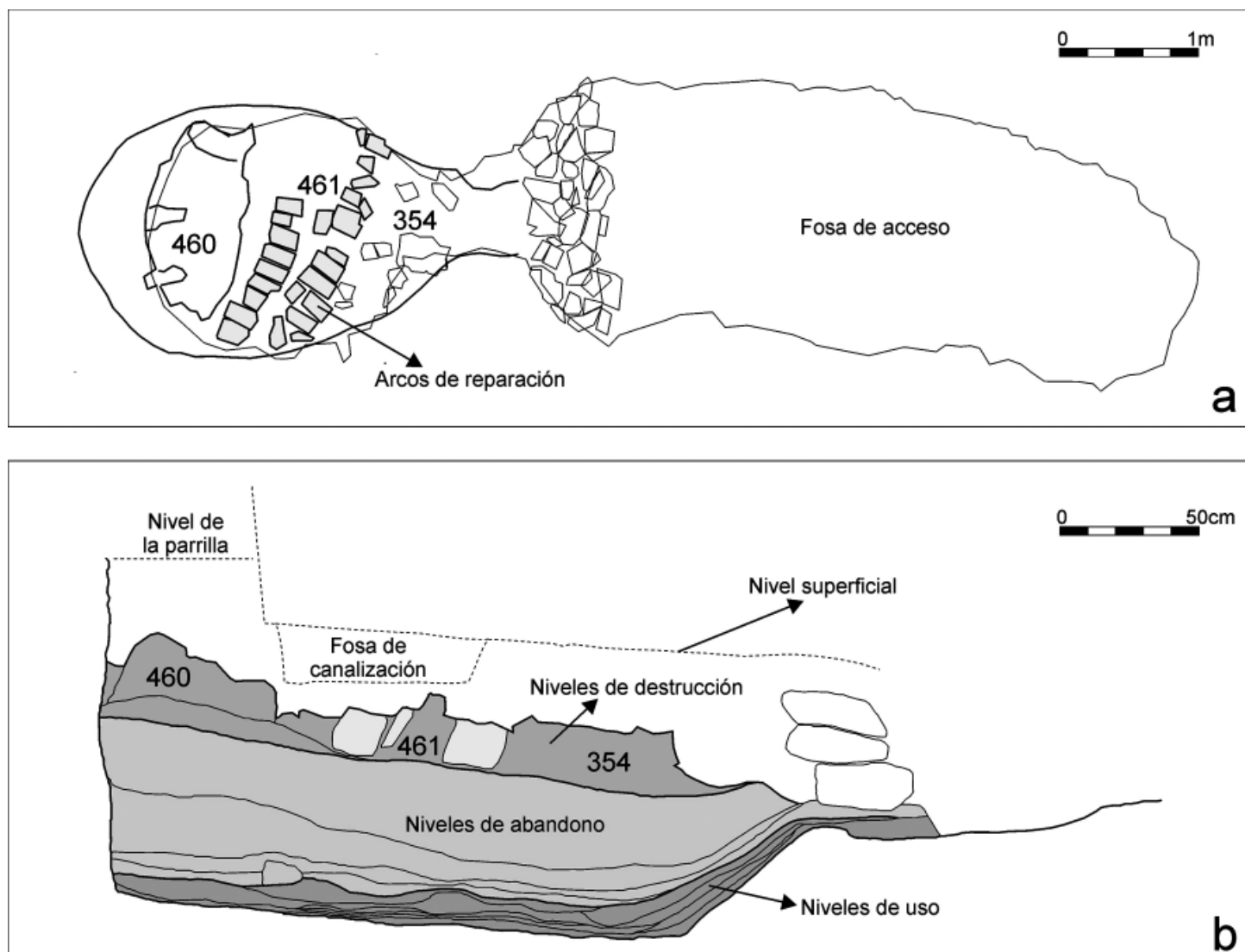


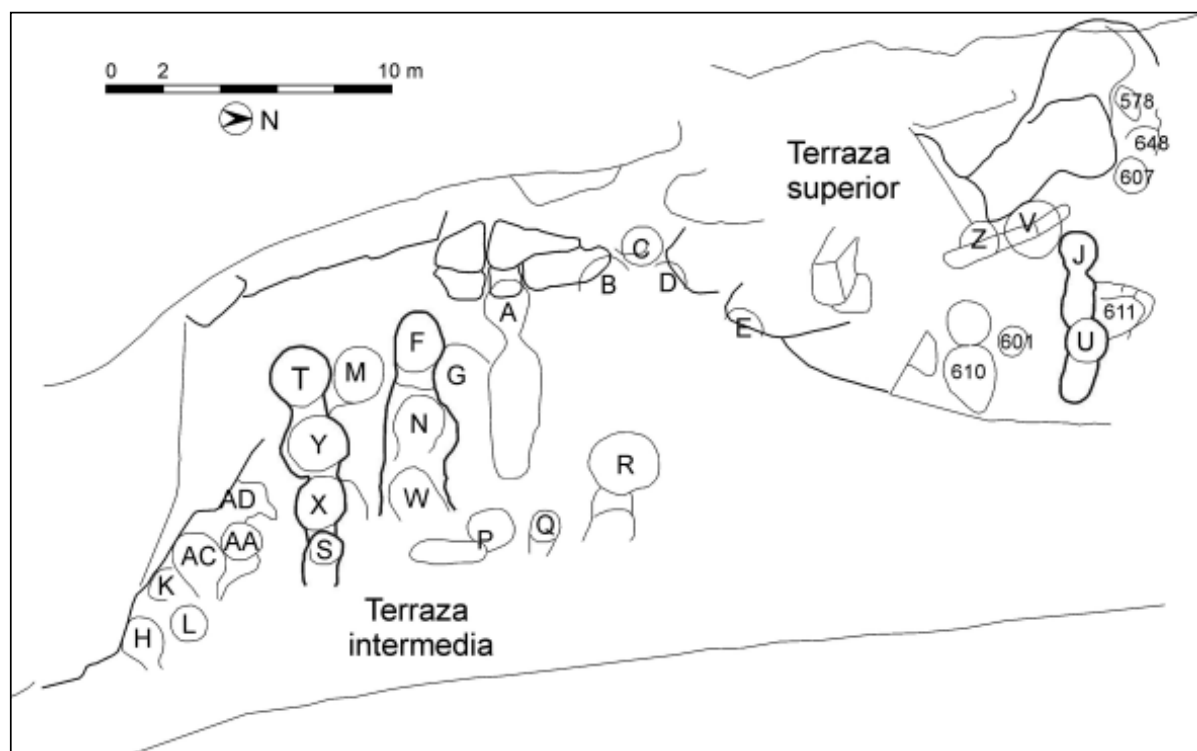

Figura 5: Planta de las terrazas superior e intermedia. Se pueden apreciar con claridad las alineaciones de los hornos S-X-Y-T,W-N-F $y \cup-$.

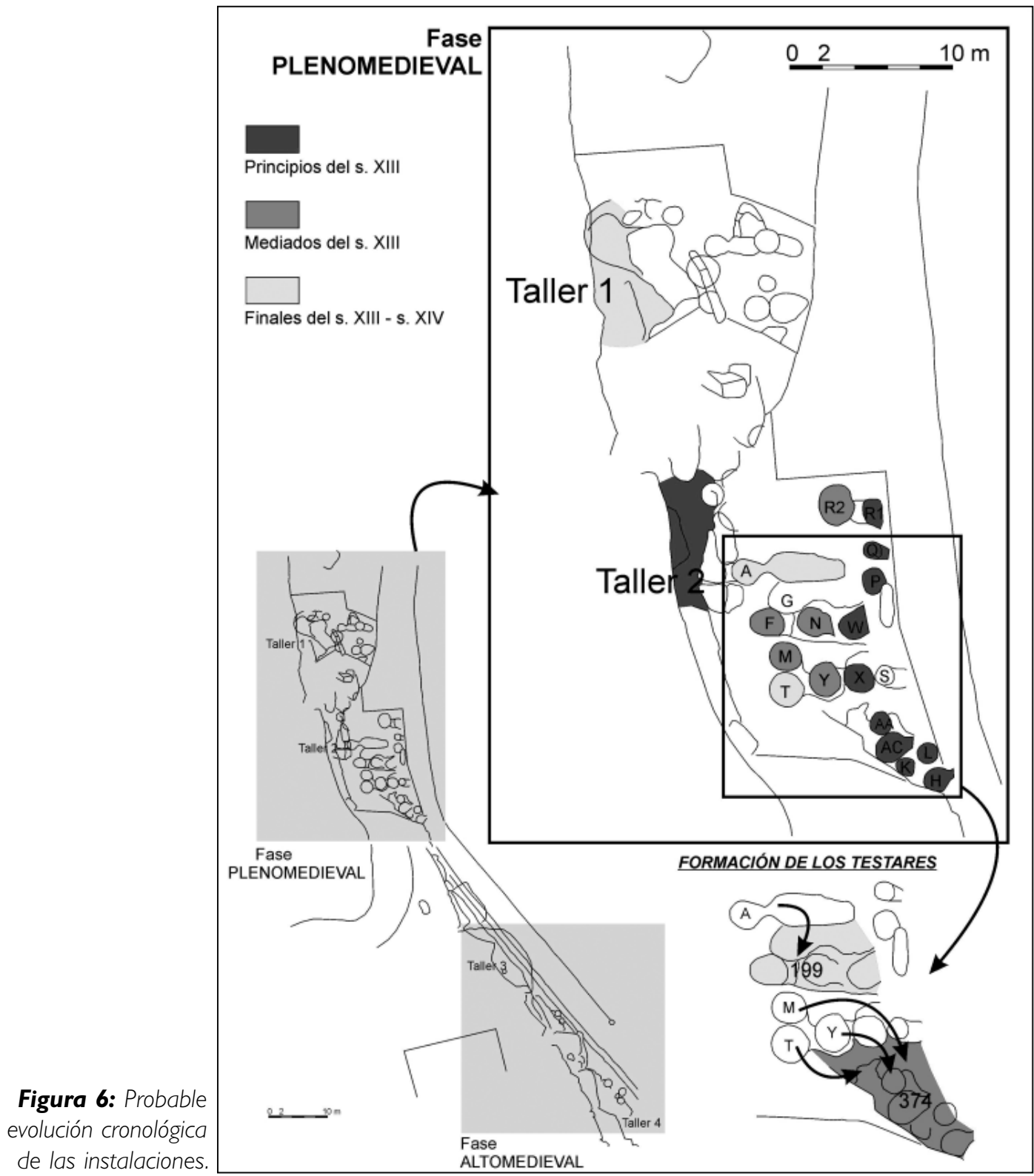




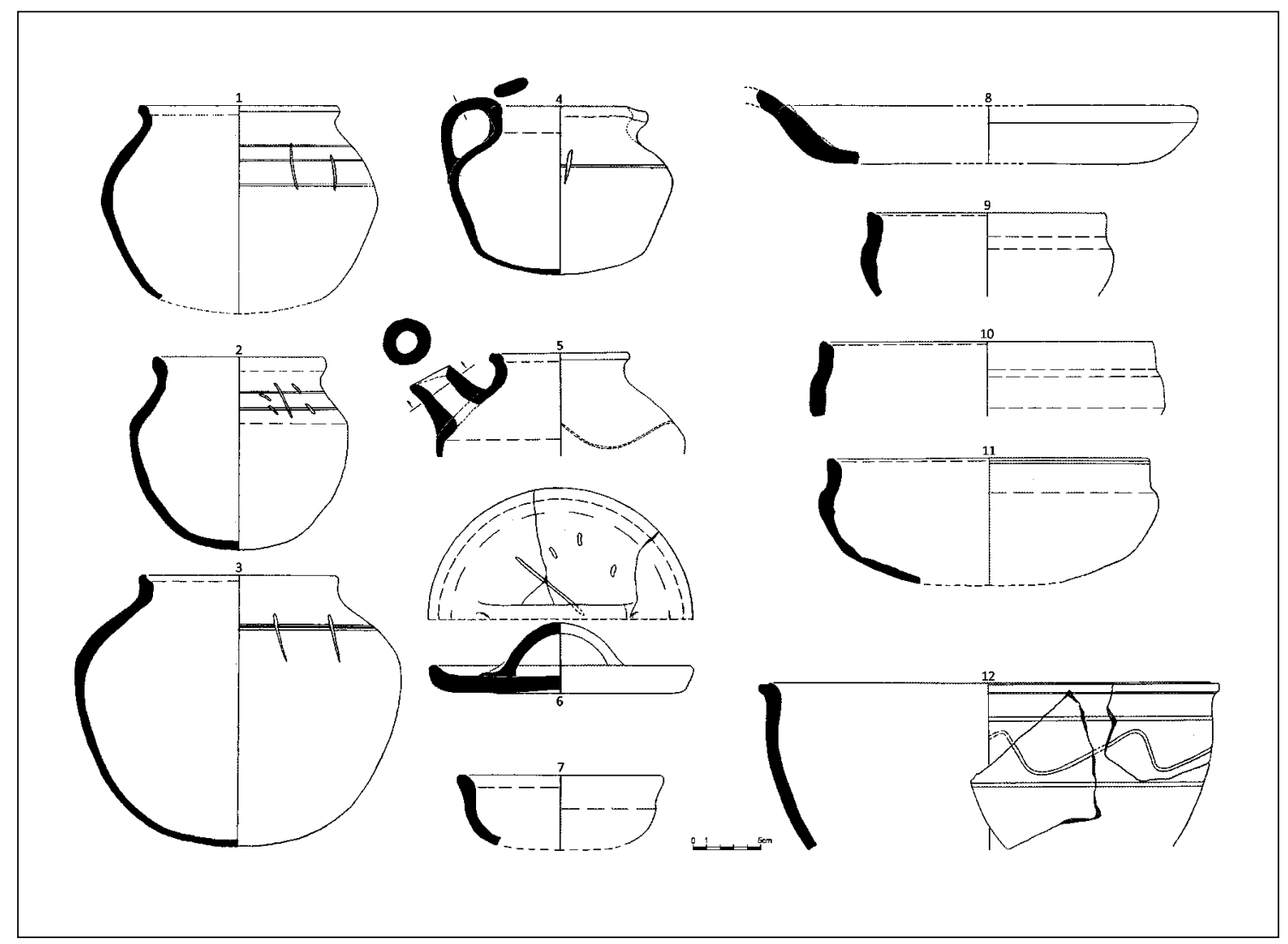

Figura 7: Representación de las principales formas completas recuperadas en Cabrera d'Anoia: ollas ( I-3), jarra (4), cannata (5), tapadera (6), escudilla (7), sartén (8), cazuelas (9-I I) y lebrillo (I 2).

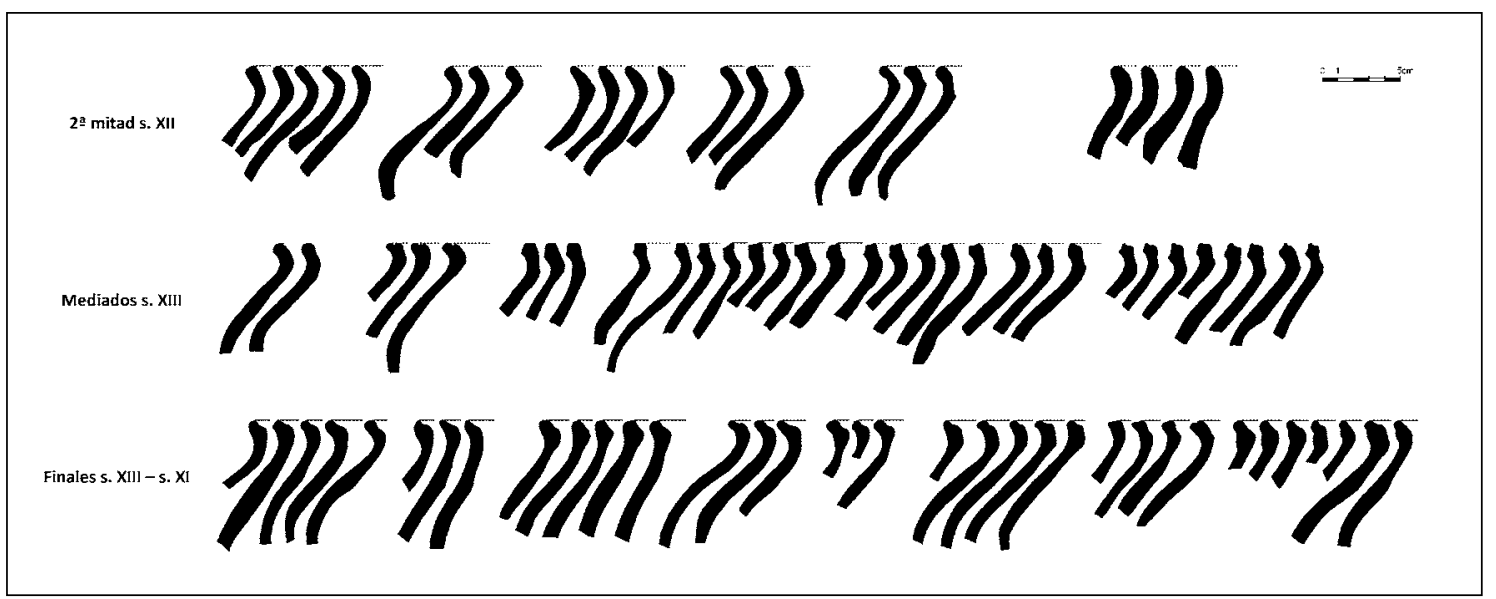

Figura 8: Evolución sutil de las formas de borde-labio durante las distintas fases de producción.. 


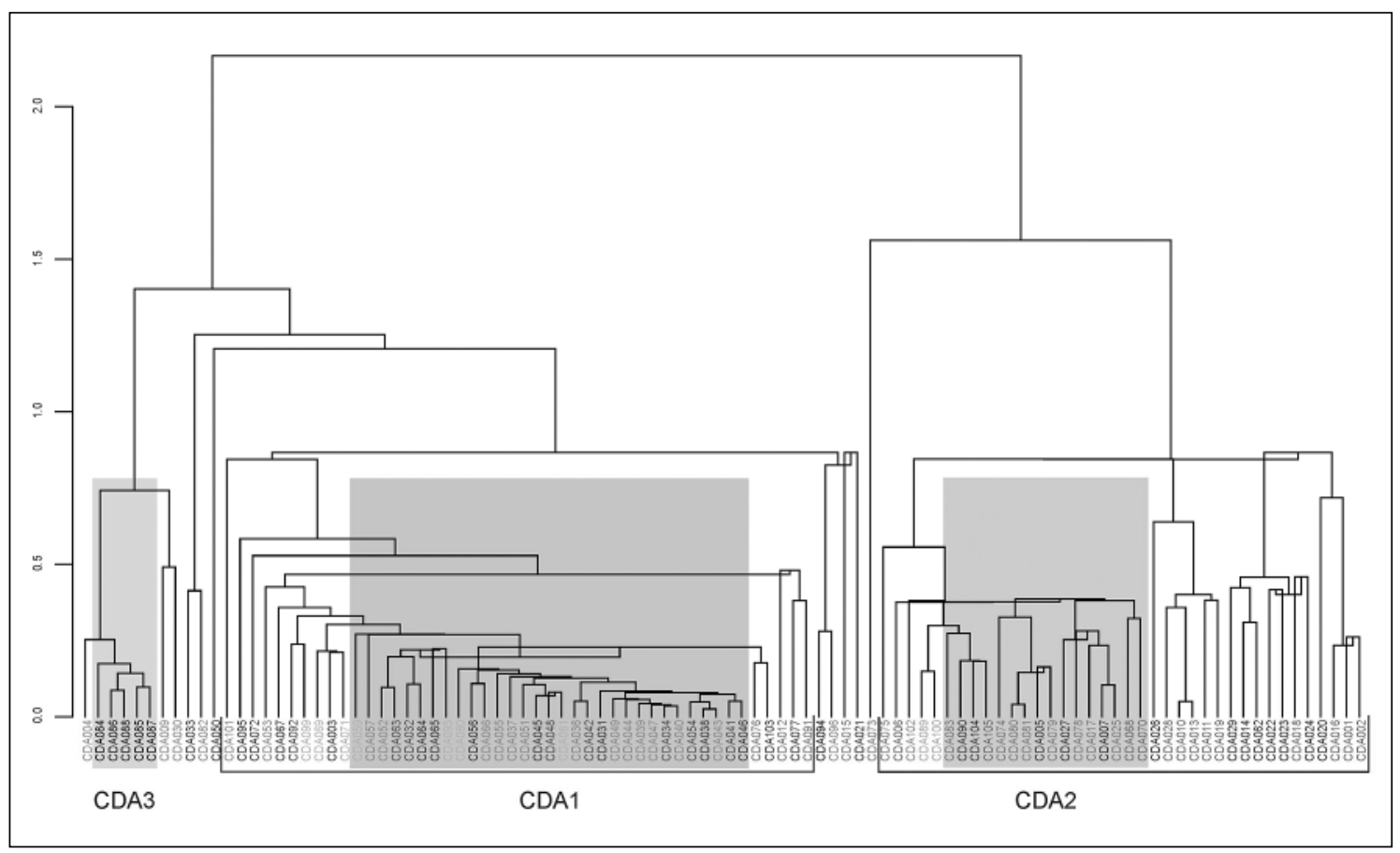

Figura 9: Dendrograma resultante del análisis de agrupamiento realizado utilizando la distancia euclidiana al cuadrado y el proceso aglomerativo del centroide por la subcomposición Fe2O3 (como Fe total), $\mathrm{Al}_{2} \mathrm{O}_{3}, \mathrm{MnO}$, $\mathrm{TiO}_{2}, \mathrm{MgO}, \mathrm{CaO}, \mathrm{Na}_{2} \mathrm{O}, \mathrm{K}_{2} \mathrm{O}, \mathrm{SiO}_{2}, \mathrm{Ba}, \mathrm{Rb}, \mathrm{Th}, \mathrm{Nb}, \mathrm{Pb}, \mathrm{Zr}, \mathrm{Y}, \mathrm{Sr}, \mathrm{Ce}, \mathrm{Ga}, \mathrm{V}, \mathrm{Zn}, \mathrm{Cu}, \mathrm{Ni}, \mathrm{Cr}$, transformados en logaritmos de razones centrados, $\sin \mathrm{P}_{2} \mathrm{O}_{5}$ y sin la muestra CDA035. El color de la etiqueta de cada individuo representa el grupo petrográfico al que queda asignado. Asimismo, los recuadros de color indican el núcleo de grupo con una homogeneidad mayor.

Figura I0: Tabla de coeficientes de los tres primeros componentes principales.

\begin{tabular}{|l|c|c|c|}
\hline & Comp. 1 & Comp. 2 & Comp. 3 \\
\hline $\mathrm{Fe}_{2} \mathrm{O}_{3}$ & 0,03 & 0,05 & $-0,06$ \\
\hline $\mathrm{MnO}$ & 0,15 & 0,14 & 0,20 \\
\hline $\mathrm{TiO}_{2}$ & 0,12 & 0,03 & 0,00 \\
\hline $\mathrm{MgO}$ & $-0,25$ & 0,07 & $-0,14$ \\
\hline $\mathrm{CaO}$ & $-0,85$ & 0,22 & 0,22 \\
\hline $\mathrm{Na}_{2} \mathrm{O}$ & $-0,02$ & $-0,29$ & 0,69 \\
\hline $\mathrm{K}_{2} \mathrm{O}$ & $-0,15$ & 0,02 & $-0,20$ \\
\hline $\mathrm{SiO}_{2}$ & 0,04 & $-0,09$ & 0,12 \\
\hline $\mathrm{Ba}$ & $-0,04$ & $-0,10$ & 0,12 \\
\hline $\mathrm{Rb}$ & $-0,05$ & 0,05 & $-0,14$ \\
\hline $\mathrm{Th}$ & 0,00 & 0,03 & $-0,04$ \\
\hline $\mathrm{Nb}$ & 0,06 & 0,04 & 0,05 \\
\hline $\mathrm{Pb}$ & 0,03 & 0,12 & 0,25 \\
\hline $\mathrm{Zr}$ & 0,20 & $-0,06$ & 0,22 \\
\hline $\mathrm{Y}$ & 0,10 & $-0,03$ & 0,16 \\
\hline $\mathrm{Sr}$ & $-0,20$ & $-0,14$ & 0,11 \\
\hline $\mathrm{Ce}$ & 0,09 & 0,04 & 0,03 \\
\hline $\mathrm{Ga}$ & 0,04 & $-0,04$ & 0,01 \\
\hline $\mathrm{V}$ & 0,11 & 0,02 & 0,00 \\
\hline $\mathrm{Zn}$ & 0,06 & 0,24 & $-0,04$ \\
\hline $\mathrm{Cu}$ & 0,13 & 0,81 & 0,24 \\
\hline $\mathrm{Ni}$ & 0,07 & 0,22 & $-0,18$ \\
\hline $\mathrm{Cr}$ & 0,14 & 0,13 & 0,26 \\
\hline
\end{tabular}




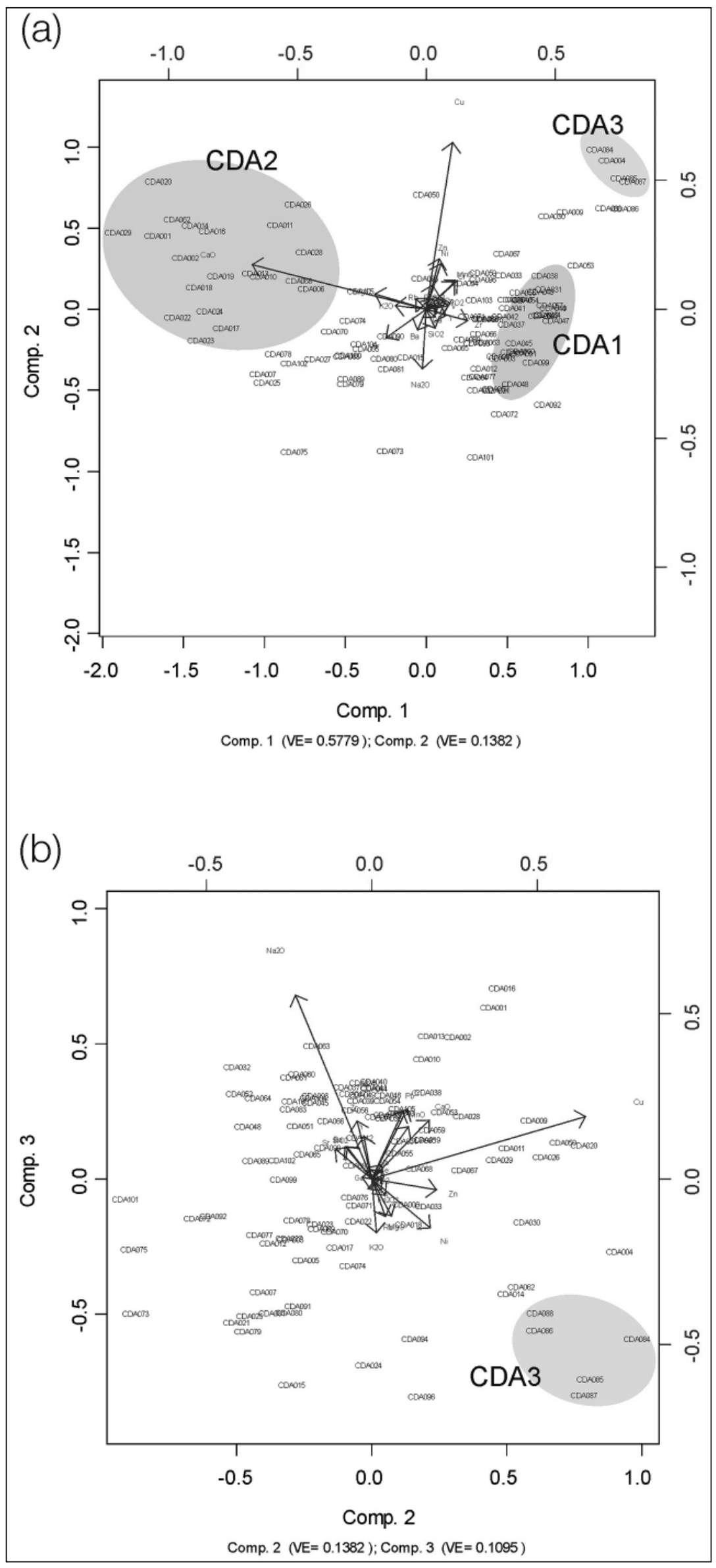

Figura I I: (a) Gráfico bivariante de la primera componente principal (Comp. I) en abscisas, y la segunda (Comp. 2) en ordenadas, que representan el $71,61 \%$ de la varianza explicada (VE); y (b) gráfico bivariante de la segunda componente principal (Comp. 2) en abscisas, y la tercera (Comp. 3) en ordenadas, que representan el $24,77 \%$ de la varianza explicada (VE). En ambos casos, las etiquetas de los componentes corresponden a los componentes transformados en logaritmos de razones empleando el $\mathrm{Al}_{2} \mathrm{O}_{3}$ como divisor.

(b) 


\begin{tabular}{|c|c|c|c|c|c|}
\hline \multicolumn{2}{|c|}{ PETROGRAFÍA CERÁMICA } & \multirow{2}{*}{ FRX } & \multirow{2}{*}{\multicolumn{2}{|c|}{ DRX }} & \multirow[b]{2}{*}{$\begin{array}{l}\text { Número de } \\
\text { dividuos asignados: }\end{array}$} \\
\hline Grupos de fábrica & Subgrupos de fábrica & & & & \\
\hline \multirow{7}{*}{ Granitoide (1) } & \multirow{2}{*}{ Granitoide y filita (2) } & \multirow{7}{*}{ CDA1 } & F1 & III. Qtz. Plg. KFs. Tlc. & 13 \\
\hline & & & F2 & III. Qtz. Plg. KFs & 10 \\
\hline & $\begin{array}{c}\text { Granitoide y micrita poco } \\
\text { frecuente (3) }\end{array}$ & & F3 & $\begin{array}{l}\text { III (dudosa), Qtz, Plg, KFs, Hr, } \\
\text { posible Mgh. }\end{array}$ & 6 \\
\hline & \multirow{3}{*}{$\begin{array}{l}\text { Granitoide, filita y micrita } \\
\text { poco frecuente (4) }\end{array}$} & & F4 & III, Qtz, Plg, KFs, Mgh, posible Spl. & 1 \\
\hline & & & F5 & $\mathrm{Qtz}, \mathrm{Plg}, \mathrm{KFs}, \mathrm{Hr}$. & 13 \\
\hline & & & F6 & Qtz, Plg, KFs, $\mathrm{Hr}$, Cal secundaria. & 4 \\
\hline & Granitoide y grauvaca (5) & & F7 & Qtz, Plg, KFs, Hr, posible Mul. & 14 \\
\hline \multirow{4}{*}{$\begin{array}{l}\text { Inclusiones } \\
\text { arcillosas (6) }\end{array}$} & \multirow{9}{*}{$\begin{array}{l}\text { Micrita, granitoide e } \\
\text { inclusiones arcillosas ( } 8 \text { ) }\end{array}$} & \multirow{9}{*}{ CDA2 } & F1 & III, TIc, Plg, Qtz, KFs, Cal, Px, posible Dol. & 1 \\
\hline & & & F2 & III, Plg, Qtz, KFs, Cal, Px (dudosos), Hem. & 15 \\
\hline & & & F3 & IIII, Plg, Qtz, KFs, Cal, Gh. & 1 \\
\hline & & & F4 & III, Plg, Qtz, KFs, Cal, Gh, Hr. & 1 \\
\hline \multirow{5}{*}{$\begin{array}{c}\text { Micrita y } \\
\text { granitoide (7) }\end{array}$} & & & F5 & $\mathrm{Plg}, \mathrm{Qtz}, \mathrm{KFs}, \mathrm{Cal}, \mathrm{Hr}$ & 11 \\
\hline & & & $\mathrm{F} 6$ & Plg, Qtz, KFs, Cal, Hr, Anl. & 1 \\
\hline & & & F7 & $\mathrm{Plg}$, Qtz, KFs, Mag, Hr o Spl, Px (dudosos). & 1 \\
\hline & & & F8 & $\mathrm{Plg}, \mathrm{Qtz}, \mathrm{KFs}$, Fo(Fe) o Fo(Mg) & 1 \\
\hline & & & F9 & Plg, Qtz, KFs, Fo-(Fe) o Fo-(Mg), Anl. & 1 \\
\hline \multirow{2}{*}{ Fracción fina (9) } & & תחמ & F1 & III, TIc, Qtz, Plg, KFs. & 1 \\
\hline & & CDA3 & F2 & III, Qtz, Plg, KFs, Hr, posible Mag. & 5 \\
\hline \multicolumn{2}{|c|}{$\begin{array}{ll}\text { Anl }=\text { Analcima } & F o(F e)=\text { Forsterita férrica } \\
\text { Cal }=\text { Calcita } & F o(M g)=\text { Forsterita Magnésica } \\
\text { Dol =Dolomita } & G h=\text { Gehlenita }\end{array}$} & inita & $\begin{array}{l}\text { KFs = Feldespato potásico } \\
\text { Mag = Magnetita } \\
\text { Mgh = Maghemita }\end{array}$ & $\begin{array}{l}\text { Feldespoto potásico } \\
g=\text { Magnetita } \\
h=\text { Maghemita }\end{array}$ & $\begin{array}{l}Q \mathbf{Q t}=\text { Cuarzo } \\
\text { Spl }=\text { Espinela } \\
\pi c=\text { Talco }\end{array}$ \\
\hline
\end{tabular}

Figura 12: Cuadro de clasificación general por grupos y fábricas en relación a los grupos composicionales y a las tres técnicas analíticas aplicadas.

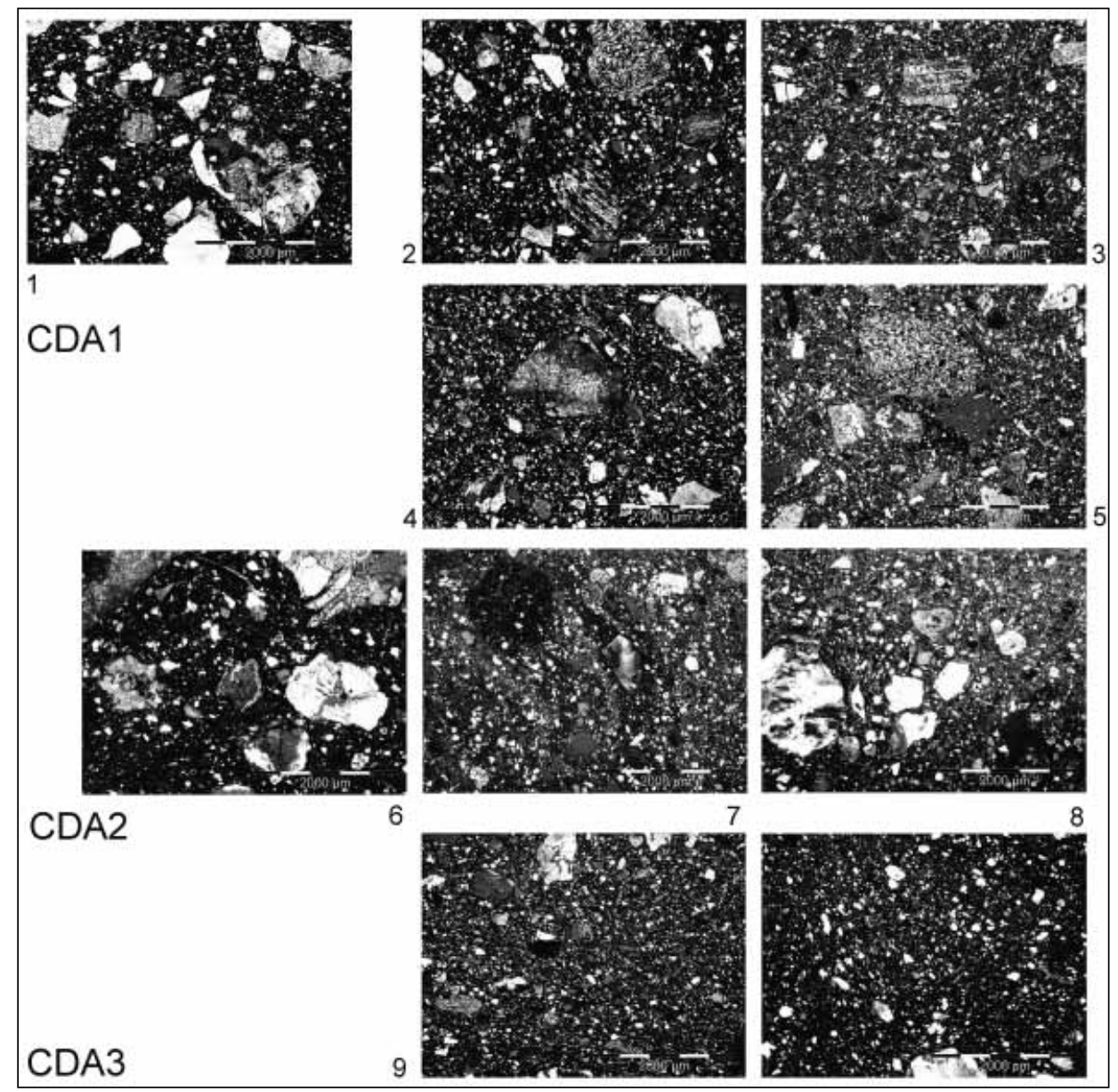

Figura I3: Microfotografias de las muestras más representativas de cada uno de los grupos petrográficos determinados observadas en lente de 40x. 


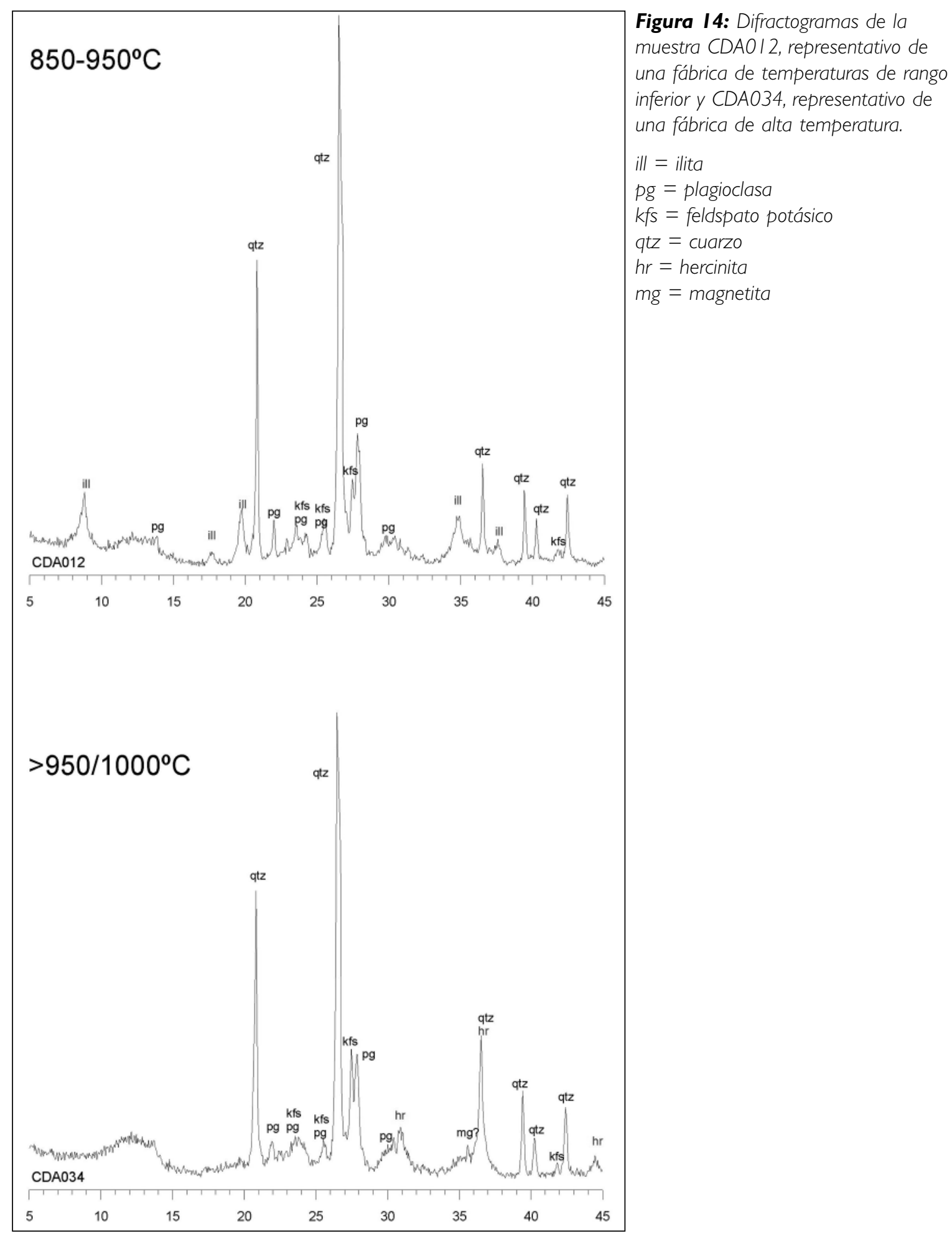




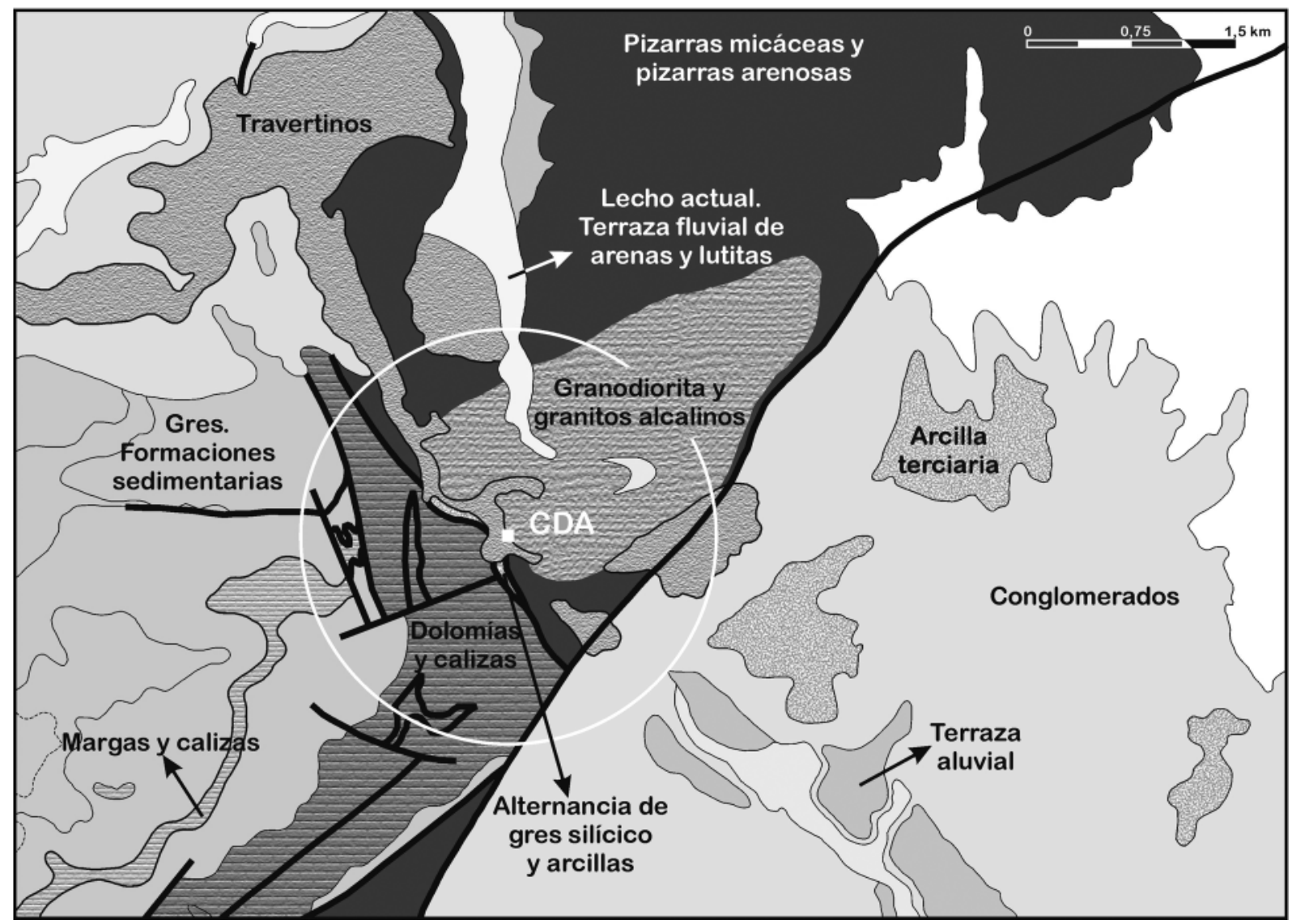

Figura I5: Mapa geológico del entorno de Cabrera d'Anoia.

Figura 16: Representación gráfica del proceso de formación de una microestructura de rollo relicto con su correspondiente identificación en microfotografía.

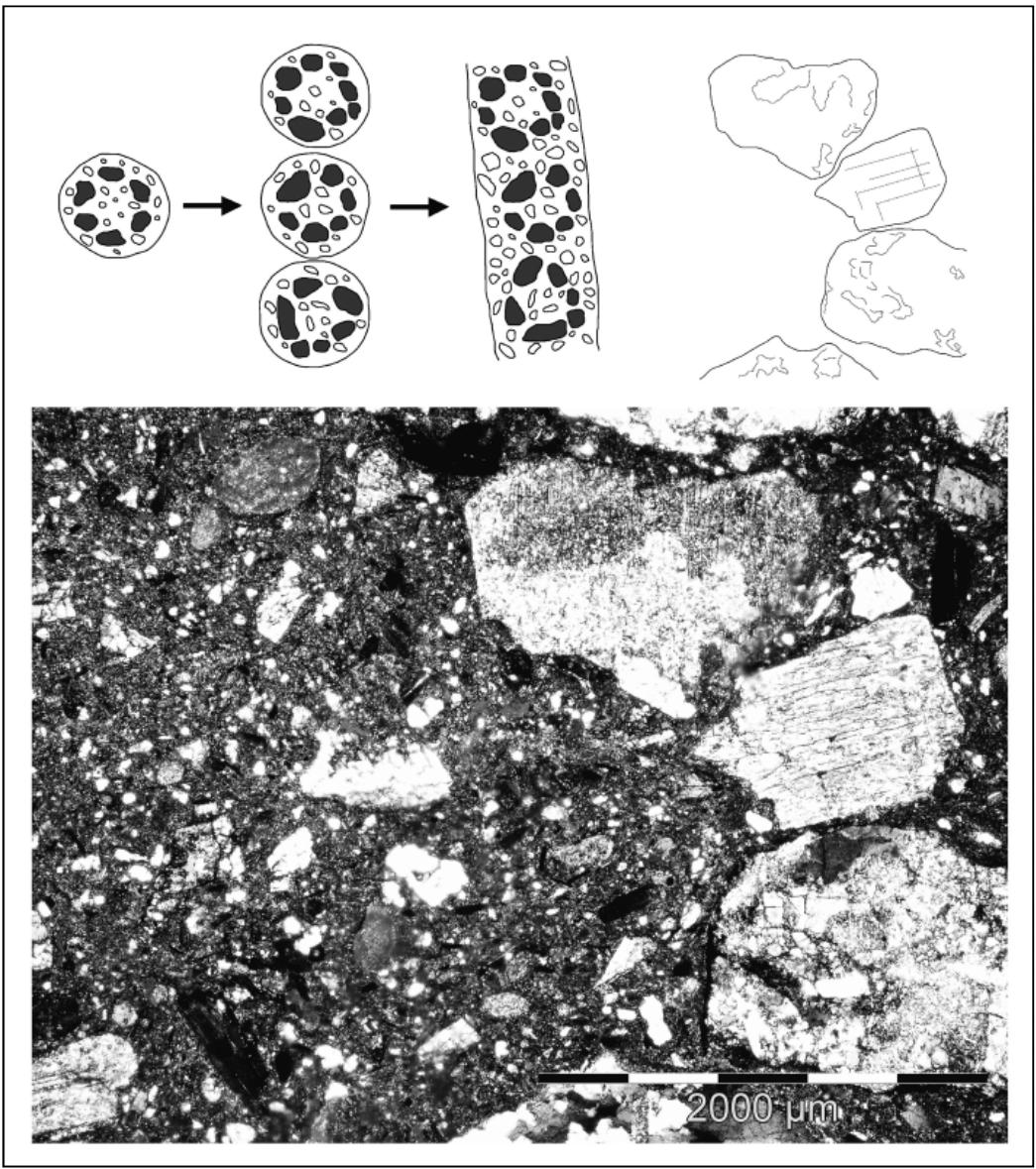




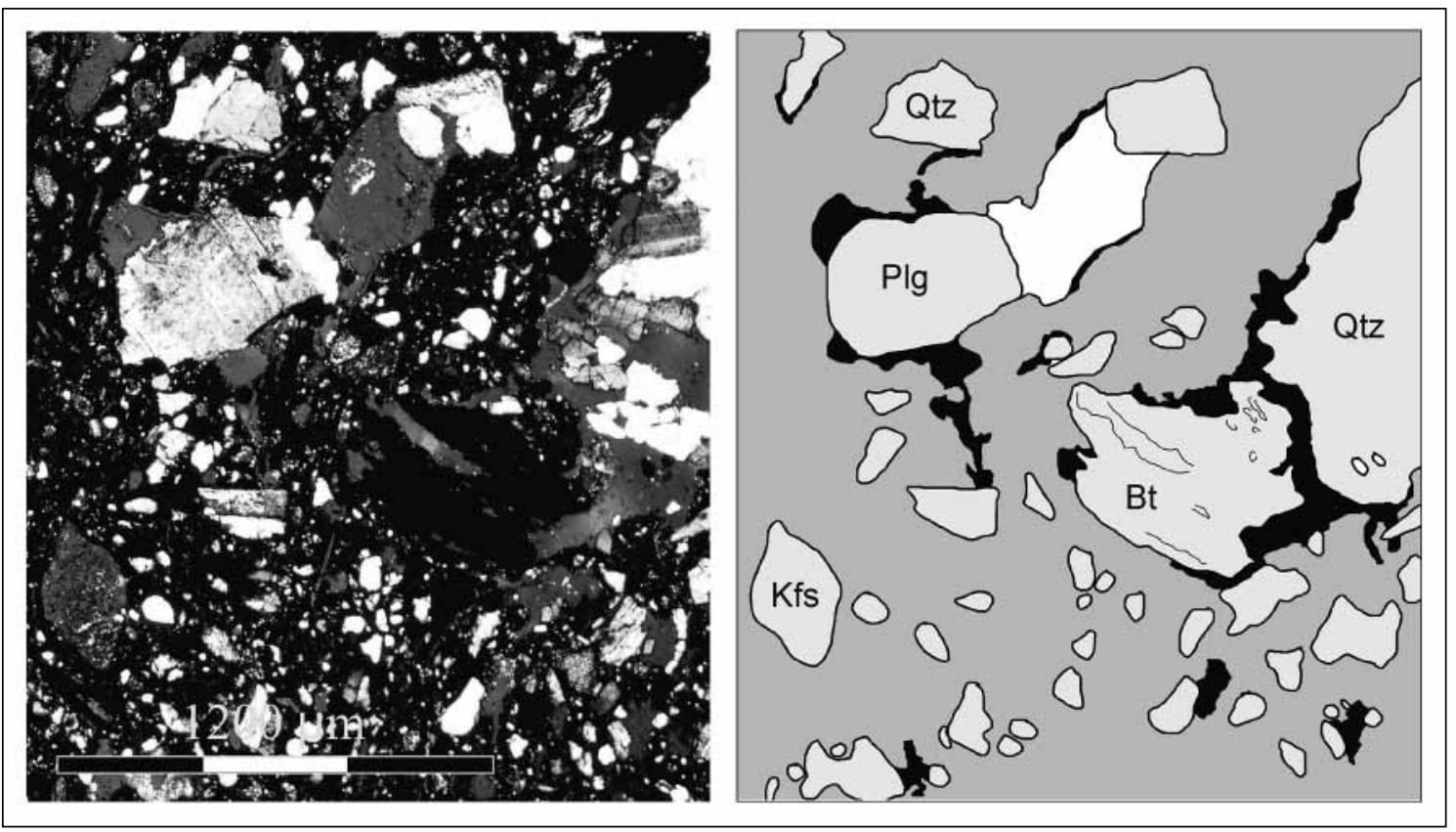

Figura I7: Microfotografía en donde se percibe el fenómeno de la porosidad generada por dilatación del cuarzo durante la cocción a alta temperatura. 